C. 2

\title{
Linking Regeneration Standards to Growth and Yield and Forest Management Objectives
}

\author{
Prepared by \\ Alberta Reforestation Standards \\ Science Council
}

For

Alberta's Minister of Sustainable Resource Development

August 29, 2001 

The Honourable Mike Cardinal

Minister of Sustainable Resource Development

420 Legislature Building

10800 - 97 Ave

Edmonton, Alberta

T5K 2B6

\section{Alberta Reforestation Standards Science Council Report}

Dear Mr. Cardinal,

We, the members of the Alberta Reforestation Standards Science Council are pleased to submit to you the results of our assessment of Alberta's regeneration standards and policies, contained in the attached report:

Linking Regeneration Standards to Growth and Yield and Forest Management Objectives.

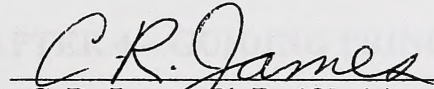

C. R. James, Ph.D. (Chair)

Professor Emeritus at the University of Alberta

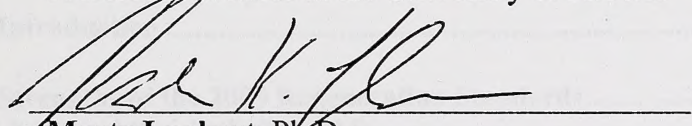

Marty Luckert, PK.D.

Professor in the Department of Rural Economy at the University of Alberta

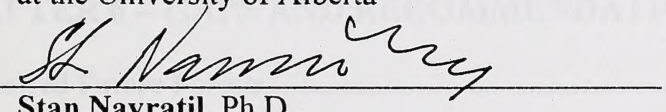

Stan Navratil, Ph.D.

Owner and Director of Silfor Consulting Co.

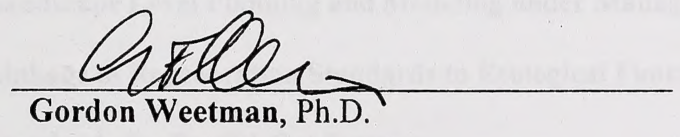

Professor Emeritus at the University of British Columbia
Victor Lieffers, $\mathrm{Ph}$.

Professor of Silviculture and Forest Ecology at the Uniyersity of Alberta

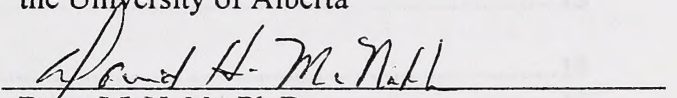

Dave McNabb, Ph.D.

Manager of Forest Resources at the Alberta Research Council

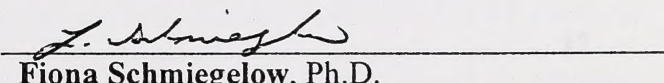

Assistant Professor of Conservation Biology, at the University of Alberta 
Digitized by the Internet Archive in 2015 
CHAPTER 1 - INTRODUCTION .........................................................................................5

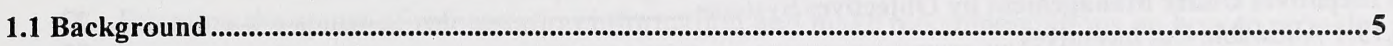

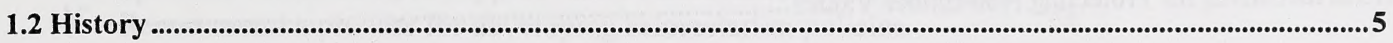

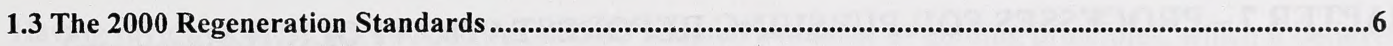

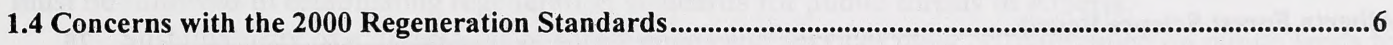

CHAPTER 2 - TERMS OF REFERENCE FOR THE ALBERTA REFORESTATION

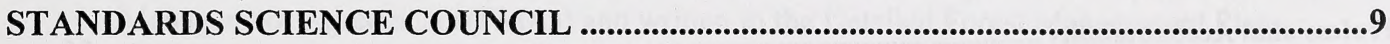

CHAPTER 3 - PROCEDURES USED BY THE ALBERTA REFORESTATION

STANDARDS SCIENCE COUNCIL

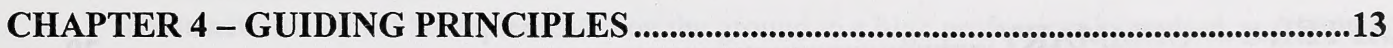

CHAPTER 5 - STRENGTHS OF THE 2000 REGENERATION STANDARDS ..............15

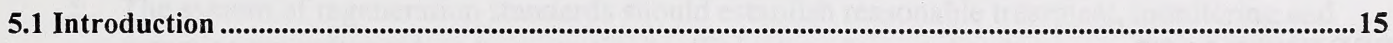

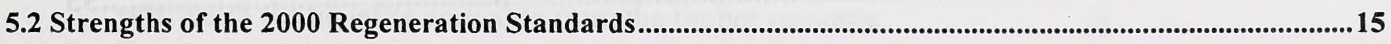

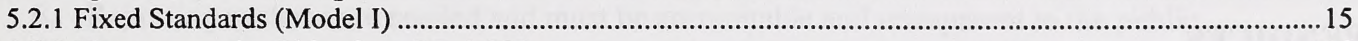

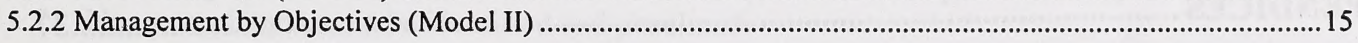

CHAPTER 6 - GAPS AND RECOMMENDATIONS ....................................................17

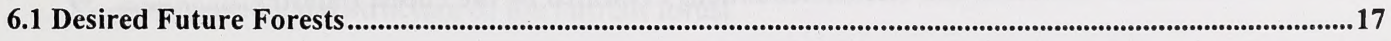

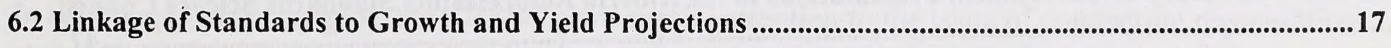

6.3 Landscape Level Planning and Modeling under Management by Objectives (MBO)...............................18

6.4 Linkage of Regeneration Standards to Ecological Function............................................................................19

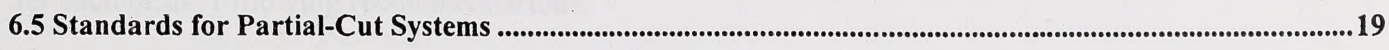

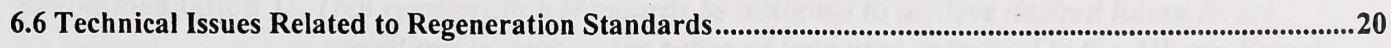

6.7 Overlapping Tenures for Hardwood and Coniferous Operators ...................................................................20

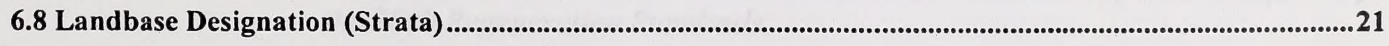


6.10 Regeneration Policy on Salvage-logged Burns.............................................................................................22

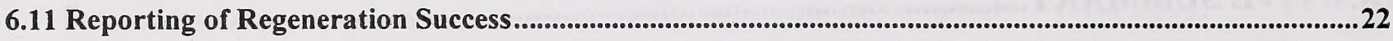

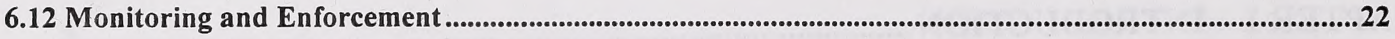

6.13 Incentives Under Management by Objectives Systems .................................................................................23

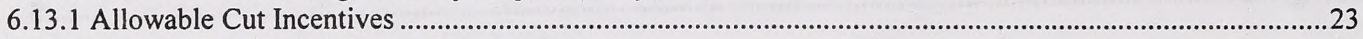

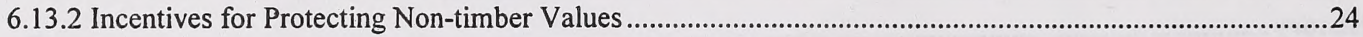

CHAPTER 7 - PROCESSES FOR PURSUING REFORESTATION POLICIES..............25

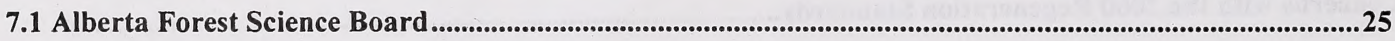

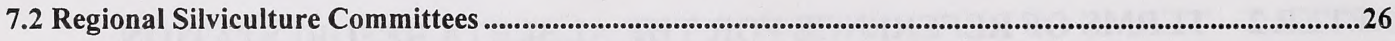

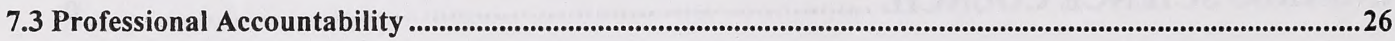

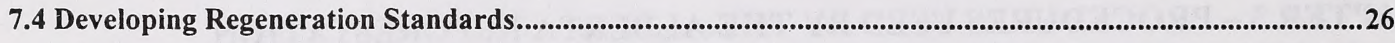

7.5 Detailed Forest Management Planning and Review Process ..............................................................................22

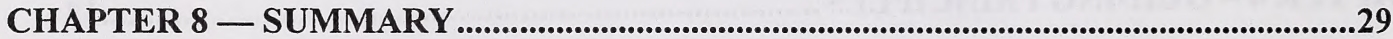

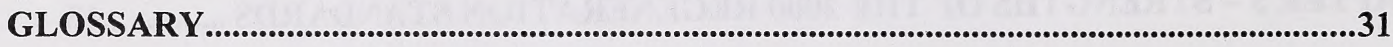

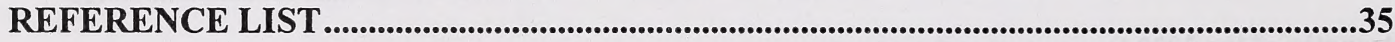

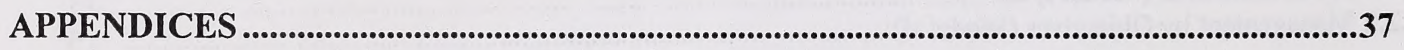

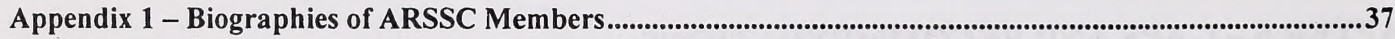

Appendix 2 - Consolidated Concerns and Recommendations Presented by the Forest Industry .....................39

Appendix 3 - Summary of Government Presentations to the Alberta Reforestation Standards Science Council A

Appendix 4 - Presentations made to the Alberta Reforestation Standards Science Council..............................55

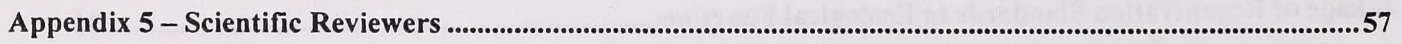




\section{EXECUTIVE SUMMARY}

The Alberta Reforestation Standards Science Council (ARSSC) was charged with providing to Alberta Environment qualitative scientific advice regarding the improvement of reforestation policy in the province of Alberta in the following areas:

1. Provide recommendations for improving the reforestation policies announced March 10, 2000.

2. Examine the status of reforestation information and make recommendations on how to provide optimum information to support future reforestation policy changes.

3. Recommend a process for developing reforestation policies.

Having reviewed these documents, the ARSSC adopted a number of guiding principles, which it believes must be followed in establishing regeneration standards for public forests in Alberta:

1. Sustainability of a diverse set of forest goods and services must be maintained on public lands for future generations based upon ecosites and desired future forests.

2. Stand level reforestation requirements must reflect landscape objectives identified in Forest Management Agreements (FMAs) and written in the Detailed Forest Management Plans (DFMPs) or other higher level plans.

3. Stand level prescriptions and performance monitoring (surveys) systems must link:

- to a predictable yield for each important site and cover type over time,

- to a desired future forest condition (e.g. composition, structure and biodiversity), and

- to non-timber values.

These activities must be implemented on the ground to a high professional standard, and include both harvesting and regeneration practices.

4. The system of regeneration standards should be structured so that tenure holders have incentives to consider benefits and costs of alternative reforestation strategies.

5. The system of regeneration standards should establish reasonable treatment, monitoring and reporting procedures; be administratively efficient; and recognize the costs of these activities relative to the benefits derivable from the timber resource.

6. Reporting systems are needed and must be accountable and transparent to the public.

7. Non-compliance must be identified and penalized.

8. The desired future forest can differ regionally and by FMA.

9. Maintaining biodiversity and ecosystem function should be a priority in development of the future forest. In the absence of specific plans, the general goal should be to reproduce the composition and structure of the current forest.

In adopting these principles, the ARSSC gave special attention to the issue of connecting regeneration standards to the growth and yield of developing forests, and emphasized the importance of Management By Objectives as part of a long-term management strategy. After extensive review of expert opinion and information presented by local stakeholders and reviewers from other parts of Canada, the ARSSC produced 23 recommendations. The report includes a background justification and further clarification for each of the following recommendations:

Recommendation 1: That regeneration standards be designed to achieve desired future forest conditions to support the range of land uses described in the Alberta Forest Legacy report.

Recommendation 2: Design a province-wide, standardized system for collection of data in support of the 2000 Regeneration Standards. 
Recommendation 3: Enhance the analytical and growth and yield forecasting capacity in the Province. This would include augmenting the modeling program and improving liaison in developing and evaluating forest growth projection systems in all currently available models.

Recommendation 4: Ensure that all forest level models are scientifically credible, functionally realistic, provide outputs (projections for objectives) that are measurable, and interface with other planning frameworks used by industry and government.

Recommendation 5: That linkages be established between the standards and the composition and structure of the regenerated stand as related to ecological function.

Recommendation 6: That stands with a substantial component of birch, tamarack, Douglas fir, or whitebark pine be treated to maintain the species, unless the Detailed Forest Management Plan designates them for species conversion.

Recommendation 7: That information be gathered on regeneration stand dynamics in non-clearcut silvicultural systems so that scientifically validated standards are developed, and that interim standards be set for these systems while this information is being collected.

Recommendation 8: Under the auspices of the Alberta Forest Science Board (see Recommendations 17 \& 18), utilize the best available knowledge to review and revise the technical details of the fixed 2000 Regeneration Standards.

Recommendation 9: That separate management of species associated with overlapping tenures be eliminated.

Recommendation 10: Where there is joint management of a landbase (see Recommendation 9), let managers and the DFMP process define the landbase strata for each particular stand.

Recommendation 11: That policies be implemented to ensure forest lands disturbed by oil and gas activities are regenerated to forests once the oil and gas activity ends. The regeneration is to meet current standards.

Recommendation 12: Revise the regeneration policy on burned areas to ensure that if they are salvagelogged, they are subject to regeneration standards.

Recommendation 13: That the provincial government report to the public, annual summary statistics of the regeneration success and achievement of the predicted growth.

Recommendation 14: Rationalize the monitoring and penalty system using available scientific techniques, rather than arbitrarily setting penalties.

Recommendation 15: That over the long term the government consider alternatives to sustained yield volume / Allowable Cut Effect policies as a basis for achieving its sustainable forest management strategies.

Recommendation 16: That as part of the Management By Objective process, all management objectives be specified in the Detailed Forest Management Plan, and appropriate monitoring and enforcement systems be established to ensure these goals are being met.

Recommendation 17: That an Alberta Forest Science Board be established, headed by a Forest Science Director. The Forest Science Director is appointed to oversee the review and approval of Detailed Forest Management Plans, and to ensure scientific credibility of the planning process.

Recommendation 18: That $a$ Growth and Yield Scientific Panel be established to facilitate research and operational growth and yield programs and improve liaison and sharing of data, concepts and procedures between the Government and forest industry. 
Recommendation 19: That the province support the development of regional silviculture committees, comprised of representatives from industry, academic/research institutes, and government, which would hold technical sessions to discuss silviculture and stand level issues surrounding Alberta's forests.

Recommendation 20: That silviculture and stand level prescriptions be supervised and signed by a Registered Professional Forester.

Recommendation 21: That detailed forest management plans be supervised and signed by a Registered Professional Forester. (Does not represent consensus opinion of the ARSSC).

Recommendation 22: That the development of regeneration standards (either government fixed standards or standards set by companies under Management by Objective) follow the steps of forecasting, validation, setting performance standards and compliance monitoring.

Recommendation 23: That a review of public input requirements for development of Detailed Forest Management Plans be undertaken to ensure that knowledgeable input is extracted from a range of publics, including local, regional, and provincial representatives. 


\section{CHAPTER 1 - INTRODUCTION}

\subsection{Background}

In Alberta, public forests are managed to produce a sustained flow of wood fibre and other resource values. Forest regeneration is a critical component in sustainable forest management. The harvesting and reforestation activities used to establish stands in the first few years of their growth have a lasting impact on stand development and are usually the most costly component of a forestry operation, considering that dollars invested are tied up for long periods. Thus, regeneration activities impact both the long-term sustainability of forests and the economic viability of forestry operations in a variety of ways.

In Canada, most provincial governments regulating forestry on public lands have regeneration standards that must be met after a forest has been harvested. Meeting the standards is meant to ensure prompt reforestation, including adequate numbers of trees with growth rates that in theory emulate or exceed natural yields. In most jurisdictions, meeting the standards is also directly linked, or assumed to be linked, to the annual allowable cut (AAC) calculations.

Forest regeneration standards are an expression by the government of the desired composition and density of future stands. In recent years, identification of the desired future forest has become increasingly complex, as forests are expected to produce a much wider range of goods and services than were historically considered.

\subsection{History}

In Alberta, reforestation became mandatory under the Forests Act of 1949 as a requirement for sustained yield management. By 1966, survey standards were implemented in an attempt to confirm that all parts of cutovers were acceptably stocked with conifers. Conifers were chosen as benchmark species to manage because of their overwhelming economic importance at the time, and the difficulties experienced in their regeneration. The first formal standard required at least $40 \%$ of mil-acre plots to contain at least one spruce or pine. The standards of the early 1970 s required at least $80 \%$ of mil-hectare plots to be stocked with at least one three-year-old or older spruce or one two-year-old or older pine. In 1977, a Regeneration Survey Manual was produced, incorporating a sequential sampling method to better assess whether stocking was achieved throughout the cutblock, and ensure that samples were statistically valid.

Cutblocks meeting the standard were assumed to achieve full crown closure at approximately one half the length of the growth cycle-with at least 800 trees per hectare. No height requirement was in placeconifer seedlings as small as $2-3 \mathrm{~cm}$ were acceptable as long as they were two to three years old.

Juvenile stand surveys were conducted in 1985 in a sample of cutblocks considered "stocked" for at least ten years. The results indicated a high mortality of what had been considered "established" seedlings. It also showed that even though some of the conifers were still surviving, they were struggling beneath competitors. In 1991, this finding led to a new set of standards that considered only seedlings expected to survive and outgrow the competition. As a result, in addition to stocking, minimum height standards had to be met by year 8, and free-to-grow (FTG) standards had to be met by year 14. FTG standards defined a maximum level of competition that a conifer tree can sustain without inhibiting growth. In essence, FTG standards required a conifer crop tree to be free of all competing deciduous trees and shrubs that are greater than two-thirds its height and located within a one-metre radius of the stem. Developed from this perspective, the 1991 standards had a bias towards the establishment of conifers. The FTG standard assumes that deciduous trees do not normally suffer from competition. 
In the late 1980 s, other changes in the forestry sector occurred that affected the regeneration standards and their inherent conifer bias. First, the development of new technologies in pulping and panel board production increased utilization of hardwoods in Alberta. By the year 2000, nearly all of the AAC of the hardwood resource had been allocated to forest companies. However, rights to the mixed species stands are now held by both coniferous and deciduous operators - their tenure often overlaps on the same piece of ground, thus complicating the decision of which tree species mix should be regenerated after harvest. Second, the objective of maintaining levels of biodiversity has been written into most company management plans. Combined, these changes led to the recognition that converting a large percentage of the landscape to relatively pure conifer stands was not desirable. The mixedwood component of the landscape was recognized as something that should be maintained.

\subsection{The 2000 Regeneration Standards}

After several years of negotiation between the Alberta Land and Forest Service and the forest industry, a new set of standards was implemented by the Province, effective May 1, 2000, called the 2000 Regeneration Standards. The most significant changes were related to the height requirements, the FTG requirements, and the definition of standards for each of four strata. In recognition of mixedwood forests, the coniferous types were divided into pure conifer (C) and coniferous-deciduous (CD). The two other recognized strata are deciduous-coniferous (DC) and pure deciduous (D). For each stand, the strata designation is determined prior to harvesting, using the leading cover type at the time of the last inventory.

The standards demand that cutovers meet reforestation standards at 8-14 years to achieve, at maturity, approximately the same composition as the pre-harvested stand. Given overlapping tenures, arguments about how the landbase is categorized were inevitable. By accepting a deciduous tree within a FTG plot circle, the 2000 Regeneration Standards also reduced, to some degree, the conifer bias of previous standards.

As with the previous standards, the development of specific targets resulted from negotiation between provincial and industrial foresters. Submissions to the Alberta Reforestation Standards Science Council (ARSSC) raised concerns that little input was garnered from other agencies and that the scientific basis for the Standards was in question. Similarly, the submissions indicated that the choice of an AAC penalty for failing to meet regeneration targets was not well rationalized.

Although the 2000 Regeneration Standards describe specific regeneration requirements (which are termed "fixed" standards, or Model I), a company may be allowed to deviate from these standards in the pursuit of biodiversity or other objectives specified within its Detailed Forest Management Plan (DFMP). In this case, alternative regeneration standards may be used where approved by the Land and Forest Service. This approach is described as Management by Objectives (MBO) and has been loosely termed Model II. Such an approach is a significant deviation from the features of the fixed standards. While $\mathrm{MBO}$ does offer possibilities for enhanced forest level planning, and greater opportunities for adaptive management, a potential risk to the forest exists if it is not implemented responsibly.

\subsection{Concerns with the 2000 Regeneration Standards}

The forest industry in Alberta expressed to the Minister of Environment several concerns with the structure and specifics of the 2000 Regeneration Standards. The details on height requirements, landbase designation, and the Free to Grow (FTG) management of mixed species stands in the new regeneration standards were among the concerns polarizing the forest industry. Consequently, the Alberta 
Reforestation Standards Science Council was established to review the scientific basis of forest regeneration policy in Alberta. 


\section{CHAPTER 2 - TERMS OF REFERENCE FOR THE ALBERTA REFORESTATION STANDARDS SCIENCE COUNCIL}

In the year 2000, Alberta's Environment Minister, the Honourable Halvar C. Johnson, issued a Ministerial Order establishing the Alberta Reforestation Standards Science Council (ARSSC) to assist him with making improvements to Alberta's reforestation policies. The body was made up of seven scientists with a wide range of disciplinary expertise and experience encompassing many types of forestry issues. The ARSSC was formally announced on August 15, 2000.

The ARSSC was charged with providing to Alberta Environment qualitative scientific advice regarding the improvement of reforestation policy in the province of Alberta in the following areas:

1. Provide recommendations for improving the reforestation policies announced March 10, 2000.

2. Examine the status of reforestation information and make recommendations on how to provide optimum information to support future reforestation policy changes.

3. Recommend a process for developing reforestation policies.

The ARSSC members were:

Bob James (Chair)

Victor Lieffers

Martin Luckert

David McNabb

Stan Navratil

Fiona Schmiegelow

Gordon Weetman
Professor Emeritus, University of Alberta

Professor, University of Alberta

Professor, University of Alberta

Alberta Research Council

Silfor Consulting

Assistant Professor, University of Alberta

Professor Emeritus, University of British Columbia

Brief biographies are included in Appendix 1 . 



\section{CHAPTER 3 - PROCEDURES USED BY THE ALBERTA REFORESTATION STANDARDS SCIENCE COUNCIL}

The ARSSC followed a formal process for gathering background information on which to base its recommendations. The Council invited presentations from all relevant sectors, including industry, government representatives, scientists and non-government organizations. This input was invaluable in developing the recommendations that follow.

Alberta forest companies with the responsibility for reforestation presented their interests, concerns, and ideas for improvement. Four questions were posed to the industry presenters in advance of their presentations:

1. How do current reforestation standards affect your ability to meet your current management objectives?

2. What changes could be made to improve your ability to meet your management objectives?

3. To implement enhanced forest management or management by objective, what kind of information and monitoring systems would you need to reliably predict regeneration performance?

4. How should regeneration standards address the issues of stand and landscape non-timber values? Do they, in your opinion?

Nine companies made formal presentations and answered questions posed by the ARSSC members. They included Forest Management Agreement (FMA) holders, quota holders, and both deciduous and coniferous operators. These sessions were audio-recorded and subsequently transcribed and summarized by Clear Lake Ltd., a consulting firm. Two field tours of reforested areas were also conducted. A summary of forest industry concerns and recommendations is included in Appendix 2.

In addition to the primary forest industry input, three non-government organizations provided written submissions to the ARSSC. Since oil and gas activities in Alberta forests result in significant deforestation, the Canadian Association of Petroleum Producers was also invited to participate, but did not respond.

The existing policy framework, its development history, and current policy initiatives are also critical to understanding the complexities of reforestation standards. Specialists from Alberta Environment (5), the British Columbia government (1), and consultants (2) were called in to make a presentation and answer technical questions. These sessions were also taped and transcribed. A summary of the Alberta Environment presentations is included in Appendix 3. Appendix 4 lists all the presenters and Appendix 5 lists the scientific reviewers.

Closed session deliberations by the ARSSC resulted in the production of a preliminary report addressing the issues of regeneration. The draft report was sent to six scientific reviewers from other provinces and the USA for their comments and assessment. Many important points were made by the reviewers and have been incorporated into this report. 


\section{CHAPTER 4 - GUIDING PRINCIPLES}

The following documents provide part of the provincial and national background material for ARSSC deliberations: the Alberta Forests Act (1), Alberta Forest Legacy (2), National Forest Strategy (3), "Sustainable Forest Management and Its Elements" from Alberta Forest Management Science Council (4), Canadian Biodiversity Strategy (5) and "Criteria and Indicators of Sustainable Forest Management in Canada" by the Canadian Council of Forest Ministers (6). Website links to these documents are included in the Reference List.

Having reviewed these documents, the ARSSC adopted a number of guiding principles, which it believes must be followed in establishing regeneration standards for public forests in Alberta:

1. Sustainability of a diverse set of forest goods and services must be maintained on public lands for future generations based upon ecosites and desired future forests.

2. Stand level reforestation requirements must reflect landscape objectives identified in Forest Management Agreements (FMAs) and written in the Detailed Forest Management Plans (DFMPs) or other higher level plans.

3. Stand level prescriptions and performance monitoring (surveys) systems must link:

- to a predictable yield for each important site and cover type over time,

- to a desired future forest condition (e.g. composition, structure and biodiversity), and

- to non-timber values.

These activities must be implemented on the ground to a high professional standard, and include both harvesting and regeneration practices.

4. The system of regeneration standards should be structured so that tenure holders have incentives to consider benefits and costs of alternative reforestation strategies.

5. The system of regeneration standards should establish reasonable treatment, monitoring and reporting procedures, be administratively efficient, and recognize the costs of these activities relative to the benefits derivable from the timber resource.

6. Reporting systems are needed and must be accountable and transparent to the public.

7. Non-compliance must be identified and penalized.

8. The desired future forest can differ regionally and by FMA.

9. Maintaining biodiversity and ecosystem function should be a priority in development of the future forest. In the absence of specific plans, the general goal should be to reproduce the composition and structure of the current forest. 


\section{CHAPTER 5 - STRENGTHS OF THE 2000 REGENERATION STANDARDS}

\subsection{Introduction}

The 2000 Regeneration Standards are an improvement over previous standards in a number of ways. They improve upon the previous fixed standards produced in 1991, and provide an important basis for further development of standards which could apply to a Management by Objectives (MBO) system.

\subsection{Strengths of the 2000 Regeneration Standards}

\subsubsection{Fixed Standards (Model I)}

As with earlier fixed standards, the 2000 Regeneration Standards are transparent and verifiable and provide a fixed target for achieving silvicultural objectives after harvesting.

The new standards are an improvement on the 1991 standards in several areas:

1. Instead of three, now four land base or "strata" designations exist - coniferous, coniferousdeciduous, deciduous-coniferous and deciduous. These strata should provide greater possibilities for mixedwood management than the previous three. The rather arbitrary mechanism for designation of strata, however, is problematic (see below).

2. The mixedwood Free-to-Grow (FTG) definition, which allows some hardwoods to grow in close association with the conifers, provides some flexibility to maintain the natural character of the mixedwood.

3. Reclassification of a cutblock into another, more appropriate, landbase category is possible.

4. The performance standard is now related to ecosite classification.

\subsubsection{Management by Objectives (Model II)}

The 2000 Regeneration Standards contain a new clause, whereby individual companies can establish their own regeneration standards, provided their DFMP has in place a well-justified alternative standard that is approved by provincial regulators. It places the primary responsibility for setting the standard for the development of the future forest on the individual managers and organizations that prepare the DFMP.

Linkage is required between the regeneration to be achieved on each cutblock and the DFMP. A policy that allows FMA holders to set their own regeneration standards requires that the linkage to the DFMP be: quantitative, rigorous, linked to stand objectives for timber and other values in an explicit and tractable way in the wood supply model, and auditable. This policy recognizes that different DFMPs could result in different standards in different areas of Alberta.

Management by Objectives has many strengths:

1. It is flexible and may be specific to the local needs.

2. It has the potential to mesh regeneration decisions intimately with higher level planning.

3. It provides incentives for increasing knowledge about how the forest grows and potentially links regeneration success with future growth and yield.

4. It better facilitates economic decisions at the forest level by linking cost of regeneration to future yields. 
5. When coupled with the previous considerations, it could facilitate constant improvements in forest management through adaptive management.

While no approved examples of regeneration standards developed for $\mathrm{MBO}$ exist, recent provincial policy changes that outline mechanisms for enhanced forest management, as well as justifications for claiming allowable cut effects (ACE), may provide a template for regeneration standards in $\mathrm{MBO}$. The $\mathrm{MBO}$ approach could, in theory, address many of the gaps noted below with respect to the fixed standards. 


\section{CHAPTER 6 - GAPS AND RECOMMENDATIONS}

Along with the above improvements, a number of gaps exist between the ideal situation and the current situation related to both the fixed and objective-driven components of the 2000 Regeneration Standards.

\subsection{Desired Future Forests}

Alberta will need a range of outcomes in the types of forest regenerated for three primary reasons:

1. The types of stands regenerated and their position in the landscape play a critical role in biodiversity and wildlife associated with the regenerating forest. Development and implementation of regeneration standards is, therefore, critical to achieving higher level planning of forests. Timber objectives cannot be isolated from biodiversity objectives.

2. Through the Alberta Forest Legacy document, Albertans have committed to maintain diverse and productive forests with "diverse social and economic benefits today and tomorrow, while at the same time retaining the ecological vibrancy" of these forests. This also means that land use would be a combination of:

- extensive land use on most of the land area,

- lands retained for heritage purposes,

- lands used for tourism, community or industrial facilities, and

- lands used for enhanced management for timber, grazing, wildlife and tourism.

3. Across the forest industry in Alberta, major differences in philosophy and forest stewardship exist. The opportunity to implement these differences is allowed in the DFMP and differences in regeneration standards are likely to be required to achieve these higher level planning objectives.

Recommendation 1: That regeneration standards be designed to achieve desired future forest conditions to support the range of land uses described in the Alberta Forest Legacy report. The range of future forests achievable within the existing fixed standards is limited. Subsequent sections will expand on specific issues related to achieving the desired future forests.

\subsection{Linkage of Standards to Growth and Yield Projections}

The current reforestation policy implies that if the 2000 Regeneration Standards are met, then the regenerated stand will recreate the natural yields of the previous stand and meet the yield assumptions of the AAC calculation. However, based on the presentations and documentation provided to the ARSSC, it appears that the information and data on the growth of regenerated stands are inadequate to properly predict which yield curve should be applied to a particular stand type and site. No verifiable linkage has been demonstrated between the 2000 Regeneration Standards' targets and the growth and yield (G\&Y) curves of the regenerated stands and AAC calculations.

Some serious growth and yield issues have been identified:

- The current tree height standards are not well justified and not well linked to AAC. Allowing a range of 4 to 8 years for completion of the survey while having a constant height standard further complicates establishing the link to the AAC.

- Regeneration surveys based on the quadrant stocking concepts are linked to predictions of future yield, without density information. Currently available models that are able to predict growth and yield for regenerated stands (Tree and Stand Simulator [TASS], Growth and Yield Projection 
System [GYPSY], and Mixedwood Growth Model [MGM]) require density data input for simulations.

- Current FTG standards are not based on data from Alberta.

Such weak linkages to growth and yield estimations leave the province and forest industry vulnerable to challenges that the forest volume production is not being sustained after cutting. This deficiency was also recognized in the 1990 Expert Panel Report in its Recommendation 27: "Early attention should be given to testing and scientifically forecasting the growth and yield of stands regenerated under current practices." The Government agreed with the recommendation in its 1990 response to the report and has supported calibration of "various growth and yield models such as MGM (Mixedwood Growth Model) and SPS (Stand Projection System)." The SPS model was subsequently found to be poorly suited for Alberta species, and has been replaced by GYPSY (Growth and Yield Projection System), a new model under development by Alberta Environment. Currently, these models are poorly linked to regeneration standards. If the regeneration standards are to be scientifically defensible, the linkages between regeneration standards, stand regeneration, and growth and yield models need to be established and refined with a standardized data-collection system.

Recommendation 2: Design a province-wide, standardized system for collection of data in support of the 2000 Regeneration Standards. Data collection systems should address specific objectives with measurable outcomes as defined by the Growth and Yield Science Panel within the mandate of the Alberta Forest Science Board (see Recommendations 17 and 18). Data collection could include both temporary sampling plots and sequential measurements in permanent sampling plots in defined strata of stand composition and ecosites. The system should facilitate the assessment of: regeneration success in response to treatments; growth performance analysis and ties to growth and yield models; spatial analysis; and silvicultural decision-making pertaining to supplementary treatments such as competition control, fill planting, and spacing. Establishment of the link between regeneration and stand yield could be expedited using retrospective research, rather than starting with monitoring of recently harvested sites. The data collection system used must evaluate and ensure that the basic regeneration standards are meeting the assumptions inherent in AAC projections. Data collection and analysis should be a shared responsibility between government, industry, and scientific community.

Recommendation 3: Enhance the analytical and growth and yield forecasting capacity in the Province. This would include augmenting the modeling program and improving liaison in developing and evaluating forest growth projection systems in all currently available models. Model development should be a shared venture by government, forest industry and research organizations.

\subsection{Landscape Level Planning and Modeling under Management by Objectives (MBO)}

$\mathrm{MBO}$ requires a definition of a desired future forest. Once defined, data linking treatments to future forest conditions will be needed. This process begins with defining data collection and sampling protocols needed to build models of tree growth under managed conditions. If an Allowable Cut Effect (ACE) is to be granted for intensively treated stands, the information required for development of standards and models will increase because they must be more site- and treatment-specific. As with the fixed standards, MBO will fail without reliable growth and yield estimations.

The models used by the FMA holder to support management plans must be transparent to, and reproducible by, outside experts. $\mathrm{MBO}$ also requires spatially explicit planning and tracking systems capable of handling databases over large areas. 
Recommendation 4: Ensure that all forest level models are scientifically credible, functionally realistic, provide outputs (projections for objectives) that are measurable, and interface with other planning frameworks used by industry and government. The government will need to check implementation of management actions assumed in the model.

\subsection{Linkage of Regeneration Standards to Ecological Function}

The fixed regeneration standards are focused on regenerating stands of a specific composition, with the primary goal of timber production. The inherent emphasis is on ensuring a timber supply rather than addressing non-timber concerns, especially at the landscape level. No specified linkage exists between meeting the fixed regeneration standards and achieving biodiversity and other ecological and non-timber goals.

Although the 2000 Regeneration Standards recognize a broader range of landbase classifications than previous policies, it is not clear whether the standards, if met, will achieve a greater variety of forest types. Mixed species blocks could be subdivided and treated to produce subsets of pure stands, especially if herbicides are used. The current Free-to-Grow (FTG) standards force intensive vegetation control on all conifer blocks, and to a lesser extent on DC and CD blocks. Hardwood control is demanded even when a moderate amount of deciduous cover could enhance tree quality and other values from the forest. Thus, the need to always meet FTG status may be in direct conflict with higher-level objectives specified in the Detailed Forest Management Plan. It is therefore important to retain the flexibility to overrule stand level regeneration rules if higher level or landscape planning justifies this action (see Recommendation 1).

Recommendation 5: That linkages be established between the standards and the composition and structure of the regenerated stand as related to ecological function. The regeneration standards represent, at best, a coarse-filter approach to maintenance of ecological function. Goals for stand structure as well as composition are necessary to ensure that the basic assumptions of this approach are being met.

Provisions are also lacking in the current standards to maintain some of the less common tree species. Even though they may be considered acceptable species in the establishment survey, birch, tamarack, Douglas fir, and whitebark pine components in cut stands may be lost without specific provisions at both the stand and forest levels to promote their regeneration.

Recommendation 6: That stands with a substantial component of birch, tamarack, Douglas fir, or whitebark pine be treated to maintain the species, unless the Detailed Forest Management Plan designates them for species conversion.

\subsection{Standards for Partial-Cut Systems}

The current standards are primarily applicable to clearcutting and no fixed standards exist for partial-cut silvicultural systems. Given the increased application of practices such as understory protection of white spruce, shelterwood, and selection systems, regeneration targets are needed in these systems.

Recommendation 7: That information be gathered on regeneration stand dynamics in non-clearcut silvicultural systems so that scientifically validated standards are developed, and that interim standards be set for these systems while this information is being collected. 


\subsection{Technical Issues Related to Regeneration Standards}

The time provided to the Alberta Reforestation Standards Science Council was insufficient to properly review and revise the technical issues related to regeneration. Consequently, much additional detailed work should be undertaken.

Recommendation 8: Under the auspices of the Alberta Forest Science Board (see Recommendation 17 and 18), utilize the best available knowledge to review and revise the technical details of the fixed 2000 Regeneration Standards. Functionally, the standards should be linked to what the future forest is to become, not what it is today. The reviews and revisions should concentrate on, but not be limited to:

- The density and stocking relationships and methods of determination (density is needed to link with G\&Y models)

- The timing of surveys in relation to time of harvest and age of seedlings (the 4-8 year range includes trees on different growth trajectories)

- The linkage to ecosite

- The effectiveness of the FTG cylinder for assessing future growing conditions for crop trees

- The aggregation of inventory stand types for the development of yield curves (how much aggregation is allowable without loss of functional reality)

- The regeneration density as it relates to yield and wood quality of future stands (volume should not be the only measure)

- Linking seedling height standards in establishment and performance surveys to allowable cut calculations

- Inclusion of different regeneration lag time for stands regenerated from seed versus planting (performance standards are maintained, but the timing of survey may be delayed if approved in the DFMP)

- The dynamics and longevity of balsam poplar and balsam fir in relation to ecosite to ensure that, where these species are used as acceptable species in the standards, they will have a high probability of survival to maturity

- Developing a better understanding of mixedwood dynamics so that mixedwood models can be developed to link the regeneration state to future stand structures and compositions. In essence we need to be able to predict the successional development of young stands of various species mixes.

- The longer term impact of standards on species composition; specifically the balance of coniferous and deciduous species in mixed wood stands.

Many of these issues will require focused research to address concerns.

\subsection{Overlapping Tenures for Hardwood and Coniferous Operators}

The provincial government has allocated coniferous timber rights, within mixedwood forest types, to different forestry companies from those allocated the deciduous timber rights. The existence of two operators managing different tree species on the same landbase has caused conflicts over the silvicultural objectives for the land. Silvicultural activities that may benefit conifers may be at the expense of the hardwood resource, or vice versa. Conifer operators argue that current performance standards for conifers are too low, while the hardwood operators do not want their hardwood trees damaged by broadcast herbicide spray that would encourage conifer growth. Under these circumstances, a single regeneration standard is not likely to be embraced by all.

Given that past tenure and landbase designation formed a fundamental basis for past infrastructure and mill investments by the industry, it will be difficult to address problems relating to overlapping tenure 
now. Nonetheless, integrated species management is a fundamental prerequisite for managing commercial timber and non-timber values.

Recommendation 9: That separate management of species associated with overlapping tenures be eliminated.

Options for integrating species management include:

- Co-management agreements between conifer and deciduous users. If effective, such agreements can allow two firms to function as one, thereby integrating the management of both species. Joint management must establish goals for the whole forest, and deciduous and coniferous users, along with relevant publics and government, must agree to these goals. Planning should work backwards from the desired future forest to establish objectives for local silviculture. Cooperative efforts in Alberta and in Saskatchewan should be examined as possible models for ways that companies with different product objectives might operate on the same land area.

- Market trading of harvesting rights. Tenure holders could trade or sell harvesting rights in order to consolidate species on a given landbase. Some incentive to consolidate should be provided by the opportunity to practice $\mathrm{MBO}$, which will require integrated species management.

- Reassignment of rights. As a more extreme measure, the province could consider re-assigning harvesting rights to coniferous and deciduous species, in order to undo overlapping tenures.

Note that all of these options will require the planning of coniferous and deciduous timber supplies and ecological function consistent with DFMP objectives.

\subsection{Landbase Designation (Strata)}

Currently, the landbase designation or strata is determined before harvest, on the basis of the dominant species composition as interpreted during the most recent inventory. The use of landbase designations by the Province (i.e., assigning stands to particular strata) has been a blunt instrument to maintain the AAC of the various timber types and the ecological function components of these forests. Mixedwood forests, as evidenced in typical mixedwood yield tables, begin with hardwood dominance, but after 50 to 60 years, shift to coniferous dominance. Furthermore, depending upon regeneration conditions, stands could have very different composition from one rotation to the next. The proportion of deciduous- to coniferous-dominated lands at the time of last inventory may, therefore, not be the best basis for deciding the composition of the future forest. With increased understanding of the dynamics of these forests, we will likely develop mechanisms better than landbase assignments to achieve these goals. In the mean time, the system of landbase designation should be retained.

Recommendation 10: Where there is joint management of the landbase (see Recommendation 9), let managers and the DFMP process define the landbase strata for each particular stand. This will provide increased flexibility for joint managers to potentially produce the range of forest conditions that will sustain or enhance the coniferous and deciduous wood supply and biodiversity of the unit. This redesignation of landbase strata could apply to both fixed standards and MBO processes. 


\subsection{Regeneration Standards on Lands Disturbed by Oil and Gas Exploration}

The 2000 Regeneration Standards currently do not require forest regeneration to be achieved on areas disturbed by oil and gas exploration and development, i.e., seismic lines, well sites, camps, etc. The requirement for reclamation of the disturbed sites is simply revegetation, not reforestation. With continued oil and gas exploration and development, this practice will gradually erode the area of forest landbase in Alberta.

Recommendation 11: That policies be implemented to ensure forest lands disturbed by oil and gas activities are regenerated to forests once the oil and gas activity ends. The regeneration is to meet current standards.

\subsection{Regeneration Policy on Salvage-logged Burns}

In Alberta, responsibility for reforestation of forest lands burned by wildfire and logged is not clear. While it is less common than in the past, it is still possible to salvage-log stands that contain a large volume of commercial wood without a commitment to regenerate the stands.

Recommendation 12: Revise the regeneration policy on burned areas to ensure that if they are salvagelogged, they are subject to regeneration standards.

\subsection{Reporting of Regeneration Success}

Summary reporting of regeneration success on a provincial basis is irregular. However, public accountability requires that such reporting occur on a regular basis.

Recommendation 13: That the provincial government report to the public, annual summary statistics of the regeneration success and achievement of the predicted growth.

\subsection{Monitoring and Enforcement}

With fixed regeneration standards, the government is responsible for establishing and enforcing the commitments. Where firms are complying only to minimum requirements, there is usually a lack of innovation in the system-decision-making is focused on minimizing costs of meeting fixed standards rather than on how best to regenerate the stand. Industrial submissions indicated that the current fixed regeneration standards were not affording them the flexibility needed to adapt to site-specific conditions or landscape objectives. In these cases, actions of a company do not coincide with what they would like to be doing, which implies that companies would only comply to the letter of the law.

A further problem arises out of the roles of industry and government in this process. Whereas industry is responsible for identifying and pursuing a desired future forest as part of the DFMP, the blueprint for creating future stands is the regeneration standard set by the government. This may create a disjunction between the higher-level goals set in the industry planning process and the lower level goals of regeneration set by the government. This disjunction may be eliminated through adoption of $\mathrm{MBO}$.

Monetary penalties currently assessed for failure to complete surveys and AAC reductions can be applied for failing to meet standards. This penalty system has not been rigorously analyzed to design penalties that suit the deficiency. Such an analysis would entail assessing probabilities of detecting regeneration 
failures and calculating related levels of penalties that would provide incentives necessary to ensure regeneration. A field of study known as principal-agent analysis could help in this regard.

In the case of Alberta Forestry, the Crown would be considered the principal, and the tenure holders the agents. Both the principal and the agent have objective functions that can be specified. However, these functions are not the same. Therefore, the Crown attempts to institute a monitoring and enforcement system that adjusts the tenure holders' objective function such that it resembles the Crown's objective function. The end result is that the tenure holders behave as if they were following the Crown's objectives.

Recommendation 14: Rationalize the monitoring and penalty system using available scientific techniques, rather than arbitrarily setting penalties. This process would involve assessing probabilities of detecting regeneration failures and calculating related levels of penalties that would provide incentives necessary to ensure regeneration goals are met.

\subsection{Incentives Under Management by Objectives Systems}

The incentives associated with a MBO system are inherently different than with the fixed 2000 Regeneration Standards. With the fixed standard, if the company disagrees with the rules, their objective becomes one of meeting the standard at a minimum cost. With the MBO system, the company sets its own objectives within the constraints of Alberta government policy. Thus, pursuit of MBO objectives is more likely to be in the company's interest. However, the incentives created by the ACE, and incentives that companies have to manage for non-timber values, may not further social interests, and need to be carefully examined.

\subsubsection{Allowable Cut Incentives}

An Allowable Cut Effect (ACE) incentive occurs when a tenure holder receives an immediate increase to its annual allowable cut (AAC) for activities that may be shown to increase future yields. Two key problems have been noted with this incentive. First, if the return from a regeneration effort is maintaining or increasing an $\mathrm{AAC}$, then volumes of timber rather than values of timber are driving the decisions of the firm. Accordingly, practices such as commercial thinning, which may decrease final harvest volume but increase quality, are not undertaken. Second, in pursuing an AAC, the attributes of current forests (i.e., amounts of mature timber) rather than the attributes of desired second-generation forests tend to affect regeneration choices. The decision to improve regeneration is, therefore, dominated by how much the harvesting of current stands may be increased, rather than considering whether investments in regenerated stands will create desirable second growth forests.

The above discussion indicates that the ACE is part of sustained yield policy that focuses on perpetuating forest volumes. In the context of sustainable forest management, which seeks to perpetuate values of numerous timber and non-timber forest resources, the focus of $\mathrm{ACE}$ on timber volumes may promote Enhanced Forest Management (EFM) investments that are not in society's best interests. To combat against incentives targeted solely at increasing timber volumes, current EFM protocols include requirements to identify impacts of increased AACs on timber quality and non-timber forest resource values, and requirements to link EFM with non-timber DFMP objectives. This planning process should include simulations of tradeoffs that include economic considerations of timber volume as well as the potential effect of increased AACs on biodiversity. This latter consideration should be examined in conjunction with the establishment of linkages between standards and composition and structure related to biodiversity issues in Recommendation 5 . 
Although the above procedures may alleviate some of the non-timber supply issues associated with the ACE, the fundamental issue will not have been addressed. The fundamental issue remains: the extent to which sustained yield drives Sustainable Forest Management.

Recommendation 15: That over the long term the government consider alternatives to sustained yield volume / Allowable Cut Effect policies as a basis for achieving its sustainable forest management strategies. The incentives provided by the sustained yield volume / Allowable Cut Effect policies framework could pose barriers for the attainment of SFM objectives. Possibilities include considering varying types of sustainability requirements that are based on features of forests other than, or in addition to, timber volumes.

\subsubsection{Incentives for Protecting Non-timber Values}

Forestry firms generally do not have clear rights to non-timber goods and services such as recreation and biodiversity. Values associated with non-timber forest resources do not contribute directly to the bottom line of a forestry firm's operations. Rather, they represent industrial obligations that must be protected in order for forestry firms to maintain access to a timber supply and markets. Therefore, it is not necessarily in their interests to link regeneration efforts with non-timber goods and services.

Despite the absence of clear rights to non-timber values, a well-designed Management by Objectives framework may result in the desired future forest, including the provision of non-timber values, through the pursuit of good corporate citizenship, which may be recognized by the marketplace and the public. However, the inevitable variability within industry regarding the quality of forest stewardship suggests that social and governmental expectations for non-timber forest resources must be clearly specified and enforced to ensure that these values are realized in the future.

Monitoring of non-timber objectives is a necessary component of $\mathrm{MBO}$, and requires that additional guidelines be established. The Alberta Forest Biomonitoring Program has developed monitoring protocols for a range of non-timber attributes, which could aid in the establishment of such guidelines.

Recommendation 16: That as part of the Management By Objective process, all management objectives be specified in the Detailed Forest Management Plan, and appropriate monitoring and enforcement systems be established to ensure these goals are being met. Tracking of goals should facilitate an adaptive management approach, whereby failures to meet objectives are detected in time to adjust forestlevel management. Trajectories for all goals should be specified-simply monitoring for changes over time is inadequate for developing a responsive adaptive management approach and implementation of the precautionary principle. 


\section{CHAPTER 7 - PROCESSES FOR PURSUING REFORESTATION POLICIES}

\subsection{Alberta Forest Science Board}

Managing for diverse objectives involves a complex planning process including science-based solutions as well as complex decision-making processes. Needs exist for:

- a rigorous and transparent evaluation of DFMPs and of the issues inherent to forest management;

- strengthening of the current DFMP approval process to ensure scientific validity of the key assumptions, methods, and conclusions;

- appropriate documentation of such evaluation and approval, and availability of this information to the public;

- identification of priority areas for planning, including input validation, monitoring, and research; and

- mechanisms for objectively resolving complex issues regarding forest management in the Province.

The Crown is clearly responsible for this process, but the best possible use should be made of expertise available from other sectors. Collectively, the process should produce independent, unbiased evaluations providing science-based recommendations and resolutions.

Recommendation 17: That an Alberta Forest Science Board be established, headed by a Forest Science Director. The Forest Science Director is appointed to oversee the review and approval of Detailed Forest Management Plans, and to ensure scientific credibility of the planning process. The Board should also identify province-wide priorities for research and development. The Forest Science Director position should be permanent and report to the Assistant Deputy Minister. The Board should be supported by Scientific Panels, as needed, to deal with specific issues. The Panels should be comprised of representatives from government, forest industry, and the scientific community, and appointed as technical experts. Areas for Scientific Panels might include, but are not restricted to: growth and yield; silviculture and stand dynamics; biodiversity; wildlife; landscape modeling; and monitoring and assessment. Strategic objectives and deliverables for panels would be directed by the Board.

An immediate need exists for a provincial growth and yield strategy to provide tools and data essential for planning and analyses and to provide direction for the growth and yield programs in the province. Provincial coordination is needed to minimize duplication of effort in growth and yield programsincluding development of yield curves, data acquisition, and calibration of models for Alberta conditions and ecosites-and consistency in yield forecasting.

Recommendation 18: That a Growth and Yield Scientific Panel be established to facilitate research and operational growth and yield programs and improve liaison and sharing of data, concepts and procedures between the government and forest industry. Panel membership should include experts in growth and yield representing the Alberta forestry sector and other jurisdictions.

Objectives of this panel should include:

1. A review of the technical aspects of the standards identified under Recommendation 8.

2. Evaluation of the scope and needs of the permanent sample plot (PSP) program in the province.

3. Establishment of task forces to develop silviculture/site information guides, tabulated for each species group, to highlight the best management information possible. 
In addition, this Panel could encourage a cooperative approach to funding the programs for specific areas of interest (Foothills Growth and Yield Association, Western Boreal Growth and Yield Cooperative, Mixedwood Association), and facilitate inter-provincial cooperation in growth and yield in the boreal forest.

\subsection{Regional Silviculture Committees}

Regeneration silviculture requires that considerable expertise and knowledge be applied to stand level planning. The Crown and forest industry need to find ways to ensure the best available information and knowledge on regeneration experience is available to foresters and technicians.

Recommendation 19: That the province support the development of regional silviculture committees, comprised of representatives from industry, academic/research institutes and government, which would hold technical sessions to discuss silviculture and stand level issues surrounding Alberta's forests. Such groups exist in other provinces and have been successful. Coordination of such groups could rest with Canadian Forest Service, Alberta Research Council, and/or the University of Alberta.

\subsection{Professional Accountability}

A need exists for accountability and professionalism in the development of forestry prescriptions and DFMPs in Alberta. A small Alberta Land and Forest Service organization (with few government foresters on the ground) is charged with monitoring huge areas of Crown forest. One possible solution is to place increased accountability for meeting the fixed standards or those customized by $\mathrm{MBO}$ onto registered forestry practitioners. In such an arrangement professionals must be accountable for their prescriptions and its implementation and display due diligence, maintain competency and be subject to inspection.

Recommendation 20: That silviculture and stand level prescriptions be supervised and signed by a Registered Professional Forester.

The following recommendation does not represent the consensus opinion of the ARSSC:

Recommendation 21: That detailed forest management plans be supervised and signed by a Registered Professional Forester.

It is important that the tenure holder be held accountable for applying the prescription consistent with the silvicultural regime, assumptions, and standards identified and committed to in the management plan.

\subsection{Developing Regeneration Standards}

A logical process for developing regeneration standards is contained in the guiding principles (Chapter 4), and is consistent with procedures outlined in a document produced by the Director of the Forest Management Division- “An Implementation Framework for Enhanced Forest Management in Alberta"(7)-which describes goals and requirements for successful implementation and technical protocols.

The technical protocols suggest the framework for assessing the management and growth of forest stands. The following steps are identified:

1. Forecasting

2. Validating

3. Setting performance standards 
4. Compliance monitoring

To date the establishment of regeneration standards does not seem to have followed these steps.

Recommendation 22: That the development of regeneration standards (either government fixed standards or standards set by companies under Management by Objective) follow the steps of forecasting, validation, setting performance standards and compliance monitoring.

\subsection{Detailed Forest Management Planning and Review Process}

The DFMP process will be the main vehicle to determine the stand and landscape level objectives for the forest unit (both timber and non-timber values) under Management by Objectives. The regeneration standards will then be developed to meet these objectives. This places much more importance on the DFMP process. Currently the DFMP process relies heavily upon local advisory groups but the public at large does not appear to have made significant input.

Recommendation 23: That a review of public input requirements for development of Detailed Forest Management Plans be undertaken to ensure that knowledgeable input is extracted from a range of publics, including local, regional, and provincial representatives. Expertise from industry, academia, and government is to be consulted in this review. Creating an informed public should be part of the process. 


\section{CHAPTER 8 - SUMMARY}

The Alberta Reforestation Standards Science Council conducted a qualitative review of the Alberta 2000 Regeneration Standards. A quantitative review was not possible due to the timelines involved. The standards make incremental improvements over previous standards, including increasing forest cover classes, site specific height standards for performance surveys, and rigorous survey protocols. However, the standards must include measures of density to ensure compatibility with most modern growth and yield models. A critical shortcoming of the standards is their failure to be linked to any model forecasting the growth and yield of regenerated stands and to validate the common assumption that the fixed standards will produce yields equivalent to natural stands. Furthermore, the standards are also lacking a monitoring protocol for determining the appropriate stand level parameters to assess whether stands are expected to achieve the broader forest and landscape level objectives in the Detailed Forest Management Plan.

Because practically all forest management currently occurs on public land, the government needs to demonstrate to the public that the land is managed according to their laws and expectations. Some but not all of the stewardship responsibilities can be transferred to forest companies. The long-term sustainability of the forestry sector depends on both government and forest companies maintaining public trust and confidence. Based on events in other jurisdictions, this is increasingly the most important factor in determining the long-term well-being of major forestry sectors. Regaining public trust once lost is a difficult task.

As Alberta attempts to advance its commitment to sustainable forest management, regeneration standards are at the heart of this issue. It is the stand level practices that ultimately determine compliance with forest level DFMP objectives. The practices to regenerate forest stands establish paths of ecological succession, and are directly linked to forecasting the growth and yield of the future forest. They are also intimately linked to managing forests for a variety of other goods and services. All harvesting should be done according to a site-specific set of silvicultural objectives for achieving timber and non-timber goals, and with an appropriate monitoring system. The DFMP should be approved by an independent body of government that is also capable of establishing scientific panels, to ensure scientific components of the DFMP are appropriate.

Management by objectives (MBO) offers increased flexibility for forest companies, but also increases the need for public accountability in its implementation. As a result, the requirements for implementing and monitoring $\mathrm{MBO}$ must be rigorous if they are to successfully gain public trust and confidence. Therefore, $\mathrm{MBO}$ is a privilege and not a right, and is gained by demonstrating a commitment to sustainable forest management, expertise in management, and an established record of performance. Consequently, the opportunity to utilize a management by objectives system must also be revocable.

Linking stand level treatments to desired future forests is going to require a better understanding of forests than is currently available. The Alberta government should immediately establish a Forest Science Board to guide the increasingly complex requirements of determining sustainable harvest levels and meeting other social concerns. The rigor of work required is well outlined in the recently approved protocols for implementation of Enhanced Forest Management (7). New fixed regeneration standards should also be developed according to these protocols. An integrated research program between industry, government and academia to develop new growth and yield models will be the most cost effective method for gaining this information. Development of growth models should be directed by a Growth and Yield Scientific Panel. The models should be subjected to external peer review, which provides 
government, industry, and the public with a measure of quality assessment and control over the basic science of yield forecasting. At the same time, this approach provides the industry with the independence to develop DFMP-specific harvest levels, and the government with a common standard to assess each DFMP independently and on its own merit.

A lack of resources and coordinated effort to develop, calibrate, and validate models for management prescriptions and ecosites is a significant shortcoming that risks the collective stability of the forestry sector in Alberta. Based on presentations by government staff, forest companies, and consideration of protocols in other jurisdictions, the Alberta Reforestation Standards Science Council believes that the government and forest sector must adopt a more rigorous, science-based process for collecting data and developing models to predict forest growth. Model validation is necessary to show the timber objectives presented in forest management plans are being met. 


\section{GLOSSARY}

Adaptive Management - A science-based process that accepts that uncertainty associated with management actions and policy choices is always high. The approach recognizes that any implementation of related activities represents an experiment, from which much can be learned through careful design and monitoring, in order to provide a feedback loop for future management and policy decisions.

Alberta Vegetation Inventory (AVI) - Forest inventory successor to Phase III.

Allowable Cut Effect (ACE) - An increase to the annual allowable cut justified on the basis of a change to one or more constraints applied in the AAC determination. ACE may result from both administrative changes (e.g., changes to landbase that result in a more regular age class distribution) and forest management practices (e.g., fertilization that increases productivity of the site).

Annual Allowable Cut (AAC) - The volume of timber that can be harvested under sustained-yield management in any one year, as stipulated in the pertinent approved forest management plan.

Annual Operating Plan (AOP) - A plan prepared and submitted by the timber operator each year.

Biological Diversity (biodiversity) - The richness, abundance, and variability of plant and animal species and communities, and the ecological processes that link them with one another and with soil, air, and water.

Clearcutting - A harvest method where all the trees in a defined area are harvested.

Coarse-Filter Approach - Conservation and management of land areas and representative habitats with the assumption that the needs of all associated species, communities, environments, and ecological processes will be met.

Crown Land - Alberta public lands administered by the Queen's representative, the Lieutenant Governor in Council.

Cutblock - A specified area of merchantable timber with defined boundaries designated for harvest.

Density - The number of trees per hectare.

Detailed Forest Management Plan (DFMP) - Long-term plan (generally ten years) used to outline higher-level management objectives and timber production assumptions for a Forest Management Agreement Area.

Ecological Integrity - Quality of natural, unmanaged or managed ecosystem, in which the natural ecological processes are sustained, with genetic, species, and ecosystem diversity assured for the future.

Enhanced Forest Management (EFM) - Alternate forest management strategies intended to provide improvements to the forest environment in terms of ecology and/or timber production. 
Forests Act, The - The legislative statute that authorizes the Minister to administer and manage the forested lands of Alberta.

Forest Management Agreement (FMA) - A legal agreement between the Crown and a corporation in which the right to harvest and grow trees on a fixed land base is granted in return for financial and other considerations.

Forest Management Division (FMD) - A branch of the Land and Forest Service.

Forest Management Plan (FMP) - A plan prepared by the Department for a forest management unit that describes how the timber will be managed.

Forest Management Unit (FMU) - A defined area of forest land located in the Green Area of the province designated by the Department to be managed for sustained timber yield.

Free to Grow (FTG) - A crop tree which has achieved the minimum height requirements and is free of competitor trees and shrubs as defined in the standards for the type of survey and the tree species.

Free to Grow Cylinder - A space defined by a fixed radius around the crop tree and above a height of two-thirds that of the crop tree.

Green Area - The portion of Crown land identified for limited residential development, and restricted from sale to private interests.

Growth \& Yield - Growth usually refers to the annual amount of wood produced on a tree or from a group of trees. Yield is the total volume available from a tree or group of trees at a time when it is considered mature or available for harvest.

Harvest Sequence - The order in which areas or compartments of timber will be harvested as established in the Forest Management Plan.

Integrated Resource Management - The management of forest resources in an area to meet the management objectives of an integrated resource plan.

Land and Forest Service (LFS) - A part of the Department of Environment in the year 2000. The Department name changed to Sustainable Resource Development in 2001.

Landscape - Land form and land cover forming a distinct pattern: portion of land that the eye can see at a glance.

Management by Objectives (MBO) - A management system which focusing on meeting defined objectives through appropriate practices, monitoring and adaptive management.

Mature/Over-mature Stands - Stands that have reached rotation age or have a reduced growth rate. Such stands normally have large mature or over-mature trees, an abundance of large live trees with heart rot, numerous snags, stubs and high stumps, and an abundance of large, downed, woody debris. 
Mixedwood Stands - Stands containing both coniferous and deciduous species.

Model I - A local reference to the existing rule-based management style requiring adherence to fixed standards with little built in flexibility.

Model II - A local reference to Management by Objectives wherein adaptive management is a crucial component.

Not Sufficiently Restocked (NSR) - The status assigned to a regeneration survey plot or harvested area when the standards have not been met.

Permanent Sample Plots (PSP) - Plots established for long-term timber growth-and-yield studies.

Phase III Forest Inventory - A provincial inventory of trees on the forested lands of Alberta.

Quota Certificate - A certificate that entitles the owner to a percentage share of the AAC of a Forest Management Unit. This percentage is translated into a fixed roundwood volume.

Regeneration - The renewal of a tree crop by natural or artificial means. It may also refer to the young crop itself.

Salvage-log - The harvest and utilization of trees which have been killed or are at risk of being killed.

Selection Cutting - An uneven-aged silvicultural system in which selected trees are harvested individually or in small groups at periodic intervals throughout a rotation; the objective is to improve the timber condition, composition, structure, and value.

Shelterwood - A silvicultural system in which trees are left standing, usually in strips designed to protect the newly established seedlings.

Silviculture - The art, science, and practice of controlling the establishment, composition, structure, health, and quality of the vegetation of forest stands.

Stand - A community of trees sufficiently uniform in species, age, arrangement, or condition so as to be distinguishable as a group in the forest from other growth in the area.

Standards - Refer to minimum strategies, practices, and requirements needed to achieve objectives. Standards include legislated requirements, regulations, established provincial policy, or operating ground rules.

Stocking - A measure of the proportion of an area occupied by trees or seedlings, expressed in terms of a percentage of occupied fixed area sample plots.

Strata - A cutblock is placed in one of four strata (C - Coniferous, CD - Coniferous-Deciduous, DC Deciduous-Coniferous, D - Deciduous) for landbase designation and regeneration survey purposes. Strata are also developed to group similar stands for inventory and analysis purposes. 
Sustainable Forest Management (SFM) - The maintenance of the ecological integrity of the forest ecosystem while providing for social and economic values such as ecosystem services, economic, social, and cultural opportunities for the benefit of present and future generations.

Sustained Yield - Theoretical calculation of the yields of wood fibre possible on a continuing basis from a forest under a specified management regime.

Tenures - Rights to harvest timber. In Alberta the main tenures are: Forest Management Agreements; Deciduous Timber Allocations; Coniferous Timber Quotas; and Commercial Timber Permits.

Timber Disposition - Licences and permits that allow timber operators to harvest from Crown lands.

Timber Operations - Includes all activities related to timber harvesting including site assessments, planning, road construction, harvesting, reclamation, and reforestation.

Timber Operator - The timber disposition holder or person responsible for controlling harvest planning and operations in the timber disposition. It also refers to those persons working on behalf of the disposition holder while conducting timber operations.

Timber Supply Analysis (TSA) - Calculations/computer models with built-in assumptions regarding forest growth patterns, used to determine AAC.

Understory Growing Stock - Trees growing under the main forest canopy.

WESBOGY - Western Boreal Growth and Yield Cooperative.

Wildlife - Any vertebrate species found in a forest environment, excluding domestic animals.

Yield Curves - The curve which represents the volume of wood (m3/ha) available over time. 


\section{REFERENCE LIST}

1. Province of Alberta. Forests Act. Queen's Printer. (http://www.gov.ab.ca/qp/ and click on Forests Act)

2. Alberta Environmental Protection. The Alberta forest legacy: Implementation framework for sustainable forest management. Pub \#I-689; ISBN\# 0-7785-0131-0.

3. Canadian Council of Forest Ministers; Natural Resources Canada, Canadian Forest Service, Headquarters, Ottawa, ON. 1992. National Forest Strategy. Sustainable forests: A Canadian commitment. (http://www.nrcan.gc.ca/cfs/nfs/strateg/control_e.html)

4. Alberta Forest Management Science Council. Sustainable forest management and its elements.

5. Natural Resources Canada, Canadian Forest Service, Headquarters, Ottawa, ON. 1995. Canadian biodiversity strategy. (http://www.NRCan.gc.ca/cfs/pub/digest/biodiver/biodive3.html)

6. Canadian Council of Forest Ministers; Natural Resources Canada, Canadian Forest Service, Headquarters, Ottawa, ON. 1997. Criteria and indicators of sustainable forest management in Canada. Technical report 1997. (Copies of this publication may be obtained free of charge from: Canadian Forest Service; Natural Resources Canada; Ottawa Ontario K1A 0E4 Canada; Fax:(613) 947-9038; E-mail: cfspolicy@am.ncr.forestry.ca)

7. Alberta Environment. 2000. An implementation framework for enhanced forest management in Alberta. (http://www.gov.ab.ca/env/forests/fmd/arssc/index.html and click on 'recommendations can be viewed here' [p 16-32]) 


\section{APPENDICES}

\section{Appendix 1 - Biographies of ARSSC Members}

\section{Bob James, PhD}

Bob James was Vice-President (Research) at the University of Alberta from 1987 to 1992, Chaired Department of Electrical Engineering from 1974-87, and has held professorial positions in electrical engineering at the U of A from 1965 through 1997.

As a chair or member of over 40 committees and boards in the past 34 years, James brings to the ARSSC a wealth of experience in policy development. Notably, James chaired the Alberta Forest Management Science Council and was a board member on the Northern River Basin Study and the Natural Science and Engineering Research Council. Currently, he is Professor Emeritus at the University of Alberta.

\section{Victor Lieffers, PhD}

Since 1983, Lieffers has been a Professor of Silviculture and Forest Ecology at the University of Alberta. He has done research on conifer seedling physiology, underplanting white spruce, mixedwood productivity and management, and pine physiology and density management. Lieffers has been editor of the Canadian Journal of Forest Research, and is active in Alberta's Registered Professional Forester Association.

\section{Marty Luckert, PhD}

Luckert is a professor in the Department of Rural Economy at the University of Alberta, specializing in Forestry and Natural Resources, Economics and Policy. He has been researching and teaching forestry economics and policy in Canada for the past 18 years. Much of his research has investigated how forest tenures across Canada may contribute to social objectives, including the sustainable management of forests. He has also worked on similar issues internationally.

\section{David McNabb, PhD}

$\mathrm{McNabb}$ is Manager of Forest Resources at the Alberta Research Council and Adjunct Professor in the University of Alberta's, Department of Renewable Resources. McNabb has conducted numerous research projects in forest soil, including many aspects of reforestation and soil productivity. For 11 years, he was on the faculty of the Department of Forest Engineering at Oregon State University with the Southwest Oregon Forestry Intensified Research (FIR) Program, where he conducted numerous research projects on site preparation and other soil and climatic factors affecting reforestation. In Alberta, his research has included developing effective soil rehabilitation practices and effects of forest harvesting equipment on soil.

\section{Stan Navratil, PhD}

Currently the owner and director of Silfor Consulting Co. and instructor at the Alberta Advanced Forest Management Institute, Navratil offers almost three decades of experience and expertise in silviculture and forest management in Canada. Prior to his existing position as a highly respected consultant, Navratil was a Professor at the Lakehead University's Faculty of Forestry, a research scientist and project leader for the Canadian Forest Service. He has also been the Director of the Forest Research Branch for the government of Alberta. 


\section{Fiona Schmiegelow, $\mathbf{P h D}$}

Schmiegelow is an Assistant Professor of Conservation Biology, within the Department of Renewable Resources at the University of Alberta. She is also Chair of the Scientific Subcommittee of the Alberta Endangered Species Conservation Committee, and Leader of the Boreal Ecology and Economics Synthesis Team, an interdisciplinary research group within the Sustainable Forest Management Network. Dr. Schmiegelow's research focuses on the effects of land-use policies and practices on wildlife, with an emphasis on northern forests.

\section{Gordon Weetman, $\mathrm{PhD}$}

Gordon Weetman has worked in industrial silviculture research for the Pulp and Paper Research Institute of Canada in Quebec, followed by 30 years as Professor of Silviculture at the University of New Brunswick and the University of British Columbia. He teaches at both Alberta Advanced Forest Management Institute and the Forest Management Institute of British Columbia. His research area is intensive forest management and forest nutrition. 


\section{Appendix 2 - Consolidated Concerns and Recommendations Presented by the Forest}

Industry

\begin{tabular}{|c|c|c|}
\hline TOPIC & CONCERNS & RECOMMENDATIONS \\
\hline $\begin{array}{l}\text { Model II } \\
\text { (MBO) }\end{array}$ & $\begin{array}{l}\text { Full range of composition, density } \\
\text { and development targets are not } \\
\text { supported }\end{array}$ & $\begin{array}{l}\text { Use Model II to provide a framework for a full } \\
\text { range of intensities and management objectives }\end{array}$ \\
\hline & & $\begin{array}{l}\text { Allow Model II: Not pass or fail; credits and } \\
\text { debits; landbase vs. cutblock; intensive } \\
\text { monitoring program; feedback and adjustments; } \\
\text { driven by DFMP }\end{array}$ \\
\hline & & $\begin{array}{l}\text { Model II (company specific objective-based } \\
\text { standards) should be an option }\end{array}$ \\
\hline Monitoring & & $\begin{array}{l}\text { Monitoring should show "we did what we said we } \\
\text { would" -include amount, timing, and location of } \\
\text { treatments } \\
\text { - Monitoring should also measure "did it turn out } \\
\text { the way we thought"-include short term regen } \\
\text { survey results, establishment, early structure, } \\
\text { spruce performance } \\
\text { - Long term monitoring compares the achieved } \\
\text { condition to the desired results }\end{array}$ \\
\hline \multirow[t]{2}{*}{ Flexibility } & $\begin{array}{l}\text { Virtually every block needs to be } \\
\text { fully stocked } \\
\text { There may be a loss of biodiversity }\end{array}$ & $\begin{array}{l}\text { Don't make the standards so high that it is } \\
\text { impossible or highly punitive to move ahead into } \\
\text { what is essentially uncharted territory }\end{array}$ \\
\hline & & $\begin{array}{l}\text { - Standards should be as flexible as possible while } \\
\text { still meeting objectives } \\
\text { - Provide more flexibility in the stocking standards } \\
\text { in the CD and DC } \\
\text { - Standards should be flexible to ensure they line } \\
\text { up with ecological management objectives }\end{array}$ \\
\hline
\end{tabular}




\begin{tabular}{|c|c|c|}
\hline TOPIC & CONCERNS & RECOMMENDATIONS \\
\hline DFMP & $\begin{array}{l}\text { Maintaining current set of cover } \\
\text { types is not a DFMP objective }\end{array}$ & $\begin{array}{l}\text { An implementation compliance phase is needed to } \\
\text { ensure that the public knows that the industry is } \\
\text { doing what it said it was going to do in the } \\
\text { management plan }\end{array}$ \\
\hline & $\begin{array}{l}\text { Reforestation standards are } \\
\text { independent of planning objectives } \\
\text { and are still focussed on an } \\
\text { agricultural view of forestry } \\
\text { The standards become the delivery } \\
\text { mechanisms for the plan } \\
\text { Standards dictate FMP objectives } \\
\text { and may conflict with non-timber } \\
\text { objectives } \\
\text { - Standards may drive harvest } \\
\text { sequence rather than the FMP }\end{array}$ & $\begin{array}{l}\text { Recognize that DFMPs and higher level plans } \\
\text { determine the objectives, not the regen standards } \\
\text { - Standards need to deliver the management } \\
\text { objectives } \\
\text { - Develop regional standards linked to management } \\
\text { objectives } \\
\text { Make the standards objective driven. If you want } \\
\text { to produce a CD, then use this standard, not be } \\
\text { forced by the standard to produce a CD because } \\
\text { you had a CD. }\end{array}$ \\
\hline & $\begin{array}{l}\text { The current average condition is not } \\
\text { well known }\end{array}$ & $\begin{array}{l}\text { - Stand structure is the most crucial component and } \\
\text { includes-amount and arrangement of residual } \\
\text { fibre; species mixtures; competitive processes } \\
\text { - Need a landscape level evaluation }\end{array}$ \\
\hline & $\begin{array}{l}\text { - Standards may not be able to } \\
\text { account for uneven-aged } \\
\text { management }\end{array}$ & \\
\hline Succession & $\begin{array}{l}\text { We are not sure how natural } \\
\text { succession will develop our stands } \\
\text { through to maturity, the standards } \\
\text { are set independent of succession } \\
\text { Succession is ignored, we assume } \\
\text { constant density and constant } \\
\text { species mixtures. } \\
\text { What is the ecological basis for } \\
\text { forcing the current strata } \\
\text { proportions on future landscapes. } \\
\text { Does not reflect natural succession. }\end{array}$ & $\begin{array}{l}\text { Keep the standards which allow trades, i.e., best- } \\
\text { suited sites and natural successional changes } \\
\text { Encourage natural recruitment and planting of } \\
\text { conifer in 20-30 year old aspen stands }\end{array}$ \\
\hline
\end{tabular}




\begin{tabular}{|c|c|c|}
\hline TOPIC & CONCERNS & RECOMMENDATIONS \\
\hline \multirow[t]{2}{*}{$\begin{array}{l}\text { Coniferous } \\
\text { /Deciduous } \\
\text { Wood Supply }\end{array}$} & $\begin{array}{l}\text { Mixedwood management goals } \\
\text { must ensure that responsibility for } \\
\text { regeneration between FMA, } \\
\text { Deciduous Timber Allocations, } \\
\text { Coniferous Timber Quotas ensures } \\
\text { that volumes relative to } \\
\text { conifer/deciduous are maintained }\end{array}$ & $\begin{array}{l}\text { Ensure a shared responsibility among disposition } \\
\text { holders for mixedwood stands } \\
\text { - Include co-ops and quota holders in the } \\
\text { development of protocols and regional standards } \\
\text { - Potential impacts on both coniferous and } \\
\text { deciduous AACs should be fully answered before } \\
\text { implementing the new standards. } \\
\text { - Issues should be resolved with a re-engagement of } \\
\text { government, industry and ARSSC. }\end{array}$ \\
\hline & $\begin{array}{l}\text { Deciduous bias in standards could } \\
\text { pose a threat to sustaining the } \\
\text { coniferous timber supply }\end{array}$ & $\begin{array}{l}\text { Standards should be viable for some companies } \\
\text { but should not be forced on everyone as } \\
\text { retroactive legislation }\end{array}$ \\
\hline \multirow[t]{2}{*}{ EFM } & $\begin{array}{l}\text { The standards may lead to a } \\
\text { reduction of deciduous supply due } \\
\text { to enhanced forest management } \\
\text { practices }\end{array}$ & \\
\hline & $\begin{array}{l}\text { Standards will inhibit companies } \\
\text { from practicing enhanced forest } \\
\text { management because they will be } \\
\text { forced to maintain static } \\
\text { composition throughout the } \\
\text { landscape }\end{array}$ & \\
\hline \multirow[t]{2}{*}{ Link to Yield } & $\begin{array}{l}\text { The link to yield is assumed } \\
\text { through meeting minimum } \\
\text { performance } \\
\text { The standards are not tied to } \\
\text { Provincial yield curves } \\
\text { AVI crown closure linked to } \\
\text { stocking linked to yield is faulty }\end{array}$ & $\begin{array}{l}\text { Minimum stocking level and performance should } \\
\text { be that needed to achieve Phase III, fully stocked, } \\
\text { natural yield curves } \\
\text { A process to validate the yield predictions is } \\
\text { needed } \\
\text { - At minimum, standards should be linked to } \\
\text { average provincial/FMP yield curves } \\
\text { Encourage development of links between regen } \\
\text { standards and yield projections }\end{array}$ \\
\hline & $\begin{array}{l}\text { Yield curves are a poor predictor of } \\
\text { stand development }\end{array}$ & - Yield in $\mathrm{m} 3 / \mathrm{ha}$ is only one component \\
\hline \multirow[t]{2}{*}{$\overline{\mathrm{AAC}}$} & $\begin{array}{l}\text { All blocks require a maximum of } 2 \\
\text { year regen lag }\end{array}$ & \\
\hline & $\begin{array}{l}\text { There is no connection between the } \\
\text { standard and AAC or AAC } \\
\text { assumptions, especially yield. }\end{array}$ & $\begin{array}{l}\text { Importance of the link between reforestation } \\
\text { standards (strategies and tactics) and AAC } \\
\text { (results) }\end{array}$ \\
\hline
\end{tabular}




\begin{tabular}{|c|c|c|}
\hline TOPIC & CONCERNS & RECOMMENDATIONS \\
\hline \multirow[t]{2}{*}{ Strata } & $\begin{array}{l}\text { C, CD, DC, D designation linked to } \\
\text { canopy, not log volume produced } \\
\text { Stands at age } 8 \text { and } 14 \text { may or may } \\
\text { not produce the prescribed strata } \\
\text { volumes or stand } \\
\text { structure/composition at maturity } \\
\text { The perception exists that if we } \\
\text { return the cover types that existed } \\
\text { at the time of inventory, then } \\
\text { volume will follow suit } \\
\text { Maintaining strata proportions does } \\
\text { not address other values and } \\
\text { contradicts AAC assumptions. }\end{array}$ & $\begin{array}{l}\text { Objectives and standards should be based on the } \\
\text { relative volumes of conifer and deciduous } \\
\text { harvested }\end{array}$ \\
\hline & $\begin{array}{l}\text { AVI crown closure under- } \\
\text { represents the conifer, and over- } \\
\text { represents the deciduous } \\
\text { component, it misses the understory } \\
\text { conifer } \\
\text { There is a lot of variability between } \\
\text { Phase III and AVI, and the } \\
\text { relationship to volume by species is } \\
\text { not consistent }\end{array}$ & $\begin{array}{l}\text { Use another method than crown closure to apply } \\
\text { regen standards-e.g., preharvest densities } \\
\text { - Provide field verification for strata definition }\end{array}$ \\
\hline \multirow[t]{2}{*}{$\begin{array}{l}\text { Segregation } \\
\text { of } \\
\text { mixedwood }\end{array}$} & $\begin{array}{l}\text { The block will be separated into } \\
\text { distinct conifer and deciduous } \\
\text { treatment units rather than treated } \\
\text { as a mixedwood } \\
\text { Has the potential to segregate the } \\
\text { mixedwood in the CD stands } \\
\text { We may be headed toward } \\
\text { developing regen standards that } \\
\text { separate a mixedwood landbase } \\
\text { rather than predicting actual } \\
\text { development on successional } \\
\text { pathways }\end{array}$ & $\begin{array}{l}\text { Promote the mixture in the mixedwood, not the } \\
\text { segregation } \\
\text { - Give greater consideration to conifer in the } \\
\text { mixedwood, due to its less aggressive early } \\
\text { growth } \\
\text { - Do not "unmix" the mixedwood Boreal forest }\end{array}$ \\
\hline & $\begin{array}{l}\text { - New standards allow, but do not } \\
\text { mandate some mixedwood } \\
\text { management. }\end{array}$ & $\begin{array}{l}\text { - Keep the standards which ensure the maintenance } \\
\text { of "incidental" deciduous in the DC and CD }\end{array}$ \\
\hline
\end{tabular}




\begin{tabular}{|c|c|c|}
\hline TOPIC & CONCERNS & RECOMMENDATIONS \\
\hline Retroactivity & $\begin{array}{l}\text { The standards are retroactive and it } \\
\text { is not reasonable to expect to meet } \\
\text { new standards on old blocks that } \\
\text { were managed to meet different } \\
\text { objectives. } \\
\text { - Retroactivity may compromise past } \\
\text { successes } \\
\text { Retroactivity will mean re- } \\
\text { stratification of past } 10 \text { years of } \\
\text { cutblocks and creates inconsistency } \\
\text { with the FMP assumptions }\end{array}$ & $\begin{array}{l}\text { Do not make } 2000 \text { Regeneration Standards } \\
\text { retroactive because of the large effort that some } \\
\text { companies have made to meet the } 1991 \text { standards } \\
\text { The } 1991 \text { performance standard should be } \\
\text { maintained for the } 1991-2000 \text { cutblocks }\end{array}$ \\
\hline \multirow[t]{2}{*}{$\begin{array}{l}\text { AAC } \\
\text { penalties }\end{array}$} & $\begin{array}{l}\text { AAC penalties for failure to meet } \\
\text { the Performance Standard are } \\
\text { disconnected from AAC } \\
\text { assumptions; are an administrative } \\
\text { burden as AACs will need to be } \\
\text { adjusted annually }\end{array}$ & $\begin{array}{l}\text { Account for failures/under-performance in the } \\
\text { next DFMP }\end{array}$ \\
\hline & & $\begin{array}{l}\text { Adaptations or adjustments to correct variances at } \\
\text { the landscape level are implemented in future } \\
\text { treatments, rather than going back to blocks } \\
\text { already treated but which have strayed from the } \\
\text { expected path-this is more cost effective }\end{array}$ \\
\hline $\begin{array}{l}\text { Admin } \\
\text { /Mgmt costs }\end{array}$ & $\begin{array}{l}\text { Administrative burden of tracking } \\
\text { re-classified and re-declared } \\
\text { cutblocks } \\
\text { Tracking and balancing each strata } \\
\text { annually will become an enormous } \\
\text { task }\end{array}$ & $\begin{array}{l}\text { Allow balancing over the landscape so that the } \\
\text { high costs of treating every hectare are } \\
\text { eliminated, making our industry more competitive } \\
\text { internationally }\end{array}$ \\
\hline
\end{tabular}




\begin{tabular}{|l|l|l|}
\hline TOPIC & CONCERNS & RECOMMENDATIONS \\
\hline $\begin{array}{l}\text { Performance } \\
\text { targets/rules }\end{array}$ & $\begin{array}{l}\text { Do not support the reduced height } \\
\text { standards for the Central } \\
\text { Mixedwood, Lower Foothills and } \\
\text { Upper Foothills ecoregions }\end{array}$ & $\begin{array}{l}\text { Use performance targets rather than minimums } \\
\text { Use landscape level objectives rather than block } \\
\text { level standards }\end{array}$ \\
\hline Link the regeneration target to a yield class \\
\hline $\begin{array}{l}\text { Deciduous stocking and height } \\
\text { requirements are too high relative } \\
\text { to the spruce heights and thus } \\
\text { prevent the development of true co- } \\
\text { dominant mixedwood stands. This } \\
\text { will lead to an increase in } \\
\text { hardwood AAC and a decrease in } \\
\text { conifer AAC. }\end{array}$ & $\begin{array}{l}\text { Height expectation is too high for } \\
\text { conifer seedlings established from } \\
\text { seed, or for seedlings browsed by } \\
\text { cattle or wildlife } \\
\text { Inclusion of balsam fir even when it } \\
\text { is not present in the overstory }\end{array}$ & $\begin{array}{l}\text { On non-competition sites, accept seedlings with } \\
\text { lower height if the treatment is prompt. Adjust } \\
\text { regen lag to allow for slow ingress. } \\
\text { Provide for aggregation of fir on a sustained yield } \\
\text { unit to achieve resource objectives } \\
\text { Address the damage to seedlings from } \\
\text { grazing/wildlife/weather }\end{array}$ \\
\hline FTG & $\begin{array}{l}\text { Allowing deciduous in the C } \\
\text { prevents spruce from achieving full } \\
\text { growth potential due to its mid- } \\
\text { tolerance to shading } \\
\text { The FTG standard excludes } \\
\text { pine/aspen stands } \\
\text { FTG in mixedwood will result in } \\
\text { tending of virtually every stand } \\
\text { The 270 degree competition-free } \\
\text { cylinder is too complicated to be } \\
\text { operational } \\
\text { Competition cylinder has not been } \\
\text { field tested }\end{array}$ & $\bullet$\begin{tabular}{l} 
Rethink the free to grow concept \\
\hline
\end{tabular} \\
\hline
\end{tabular}




\begin{tabular}{|l|l|l|}
\hline TOPIC & CONCERNS & RECOMMENDATIONS \\
\hline $\begin{array}{l}\text { Survey } \\
\text { design }\end{array}$ & $\begin{array}{l}\text { Standards don't promote early } \\
\text { stand intervention/treatments }\end{array}$ & $\begin{array}{l}\text { Assess establishment at 3 years, performance at } \\
10 \text { years }\end{array}$ \\
\hline & \begin{tabular}{l} 
- $\begin{array}{l}\text { Assess performance with calliper, leader length, } \\
\text { or Height/Diameter Ratio } \\
\text { Measure root collar diameter to determine actual } \\
\text { tree volume } \\
\text { fail the performance survey because } \\
\text { the time frame has not been } \\
\text { extended so the newly planted, or } \\
\text { newly fertilized tree has time to } \\
\text { catch up to the height required by } \\
\text { year 14 }\end{array}$ \\
\hline
\end{tabular} & $\begin{array}{l}\text { The assessment protocol needs to be sensitive to } \\
\text { the silviculture regime- specific for stocking, } \\
\text { density, height, species composition }\end{array}$ \\
\hline $\begin{array}{l}\text { Acceptability of plots falling on } \\
\text { Sensitivity of design, i.e., stocking } \\
\text { for smaller block sizes }\end{array}$ & - $\begin{array}{l}\text { Delete plots falling on seismic lines which must } \\
\text { be kept open for access }\end{array}$ \\
\hline
\end{tabular}




\section{Appendix 3 - Summary of Government Presentations to the Alberta Reforestation Standards Science Council}

\section{CHANGES NEEDED}

5 Basic areas requiring change are:

1. The area of integrated mixedwood management;

2. Verification of managed stand growth and yield assumptions;

3. Detailed forest management plan specific reforestation performance assessments;

4. A process that monitors and assesses the delivery of reforestation objectives as opposed to the one that specifies the objective; and

5. Targets based on sound data.

Improvements suggested:

1. Develop DFMP integrated mixedwood management objectives (where appropriate) agreed to by all stakeholders and then design reforestation assessment standards by DFMP.

2. Support stand-level check off requirements with a sustained yield unit-level (either FMU or FMA depending on circumstances) monitoring system.

3. Replace minimum requirements with an acceptable range for individual stands, plus define an average forest-level target for each reforestation strata.

The possible ways of improving are to:

1. Assess achievement of growth and yield expectations at the forest level by quadrant production period, which is every five years in Alberta

2. Integrate reforestation assessment procedures with a growth and yield monitoring protocol

3. Require long-term growth and yield monitoring in addition to establishment and free to grow check-offs

4. Adjust approved harvest levels when DFMP objectives are either exceeded or not achieved (by $10 \%$ ?)

5. Develop new reforestation targets that allow for a successional development of stands

6. Initiate a managed stand PSP program that can capture the ingress and mortality information

7. Establish a range of stand level targets that are appropriate for the delivery of a forest level target

8. Establish a managed stand growth and yield monitoring program to verify that targets are being achieved or realign the targets

\section{DATA UTILIZED TO DEVELOP 2000 REGENERATION STANDARDS}

1. RYSI (Regenerated Yield System Inventory)

- 1056 cutblocks with 12-20 plots per cutblock

- Measured: ecosite; crop tree height, increment, RCD, condition; competition; density by species by height classes (5); age (although proven to be highly variable against destructive sample); origin of crop tree

2. SDS (Stand Dynamics System) and Monitor Plots (regenerated PSPs)

- 360 plots, many exceeding 10 years in age

3. RPM (Regeneration Performance Monitoring PSPs)

- 152 plots, 5 yr remeasurement on all, 8 yr on about half

- used to provide reference for planted spruce performance

4. Operational Regeneration Surveys

- 1026 surveys

- used for sensitivity analysis for variations on proposed standards 


\section{REGENERATION SURVEY DATA AND ANALYSIS GAPS}

- A very real problem is the data used is historical. Treatment methods and planting stock have changed (improved) dramatically.

- Plot system changes were not addressed. A larger plot size would be better at predicting stocking of mature stands. Stocking is not independent of height, because if a tree doesn't meet minimum height it does not contribute to stocking.

- Need to study the relationship between allowable NSR patches and what can be found in the existing forest, in the context of merchantability criteria and assumed rotations. A study is needed into potentially productive voids in mature natural stands, referenced somehow to recent burns.

- Need to study the relationship between early stocking as per mil-ha plots and expected yield and species composition at rotation.

- Need to study the relationship between minimum heights, survival and development of trees. Consider other measurable criteria of trees other than height.

- Need to study the trends in mortality and height development for newer regenerating stands.

- Need objective information regarding early development of fire-origin stands to emulate natural yields.

- Need to know what level of yield and species composition will result, on average, from meeting the minimum requirements on a majority of blocks.

- Density was not incorporated into any but the deciduous standard, yet density is a prime driver of most or all regenerated yield models.

- Height to root collar ratios are proposed as another method of determining FTG status.

- Many species and subregion/drainage combinations had little or no data associated with them.

\section{DATA FOR THE FUTURE}

- Survey information is captured on every single cutblock that is harvested in the province to evaluate stocking, the species mix, and since 1991, heights. Require identification of what additional information is needed to confirm the growth and yield assumptions.

- Height and density data are now collected on all species present on all plots, as well as ecosite data on most. It will be something like 2500-3000 (this number may be low) cutblocks per year at 60 plots per block. The purpose is to place the data in a growth and yield model and make projections on it. A consistent ecological classification can be used to spread those numbers and plots across a large number of companies.

- Government has access to all of the company data that is used in forecasting timber supply analysis. If companies have PSPs, government may have access to the raw data, the compiled data, the yield curves, the timber supply analysis, the landbase net down.

- Most companies view data collected as a corporate asset. Government wants to take all of that raw data, and produce, through the mechanics of our data sharing agreements, a set of regional volume tables and yield curves. In the non-FMA management units government forecasts the harvest levels based on its own yield estimates.

- Some companies have sold their data to other competing interests with terms and conditions on how that data can be applied. The Foothills Growth \& Yield Association is a pretty strong template for what can be done if there is a collective will.

- Relatively new FMA holders in the province (with less than 10 years worth of history) just don't have the long-term PSP data bank to prove up some of the yield assumptions.

- It is not possible to measure every single cutblock and have a PSP or series of PSPs in each block. Individual cutblocks must be grouped into strata (with an appropriate number of sampled blocks in each?) and linkages made between each cutblock, regenerating strata and ultimately the growth and yield curves over the long run. 
- In developing a matrix, there are four broad cover groups, C, CD, DC and D. Added to that - in the pure conifer, you would separate out white spruce, black spruce, pine. In the mixedwood you would probably want to differentiate between aspen mixedwood and pine mixedwood. You may want some separation of balsam poplar versus birch versus aspen and you would have to multiply by sub-region and timber productivity rating (TPR). There is no point putting any matrix cell there if there is only 5,000 hectares only in the province

- A database would have to be collected or created for height growth in juvenile stands and relate those to managed stands PSPs. Or if it is felt there are too many growth and yield curves, strata agreement would be needed as to how certain strata could be rolled up into measurable strata.

- One would ideally have to have a long-term series of regenerated PSPs and an appropriate mix against the strata that are being harvested and the treatments that are being applied to enhance this whole process.

- An ecosite classification system exists for Alberta, so it could provide the framework for building the strata needed.

- The new regeneration standards require that the plot-level data be submitted in a standard electronic format for all blocks surveyed starting this year. This data is intended to allow us to make realistic assessments of the growth and yield response for operators, relative to that assumed by their AAC.

- Government is continuing to re-measure, to the limit of funds, its standing timber and regenerated PSPs. These are on older management regimes and will lose utility over time as management changes.

- Industry is beginning to commit to establishing regenerated PSPs in support of the specific objectives of the operator.

\section{MODELS}

- The fundamental silviculturalist premise in the old standards was that meeting the standards would result in replicating the fully-stocked natural yields of the fires-origin standing forests. The goal was to maintain or increase the relative proportion of conifer in the AAC, .

- No model can be assured of making projections which are accurate. Most models may overestimate forest level growth and yield because most are designed to operate on a stand level and do not account for forest-level impacts. BC models are designed to be used with operational adjustment factors (OAFs) to account for this.

- In only in a few cases, where companies actually have PSPs on regenerating stands, can they confirm the height trajectory and the site index.

- Through a model like MGM we can start to look at the cause and effect relationship of different starting densities for spruce versus aspen.

- In the long term, the biggest problem with modeling, in Alberta and most places, is a lack of data, especially on the effects of various kinds of silviculture treatments. Government wants to work cooperatively with other agencies. Data acquisition is costly, storage and processing is also expensive; also, there are a limited number of people available who can do that work.

- Most of the work that government staff does is focused on reviewing empirical type yield curves that have come in from industry.

- Alberta is moving toward more of an ecologically based approach, using the natural regions and subregions of Alberta. We have also developed associated site indexes and taper curves so we have individual tree volume tables based on ecological regions for the province, of which there are 6 regions and 20 sub-regions and, in one of those regions, there are about 8 districts. The 6 regions and 20 subregions include those grasslands for which we don't have tree volume nor site index curves. Provincial models can be applied to trees within those areas.

- Both MGM and the aspen version of Stand and Tree Integrated Model (STIM) handle aspen. Unfortunately, STIM is not maintained by anybody anymore. 
- TASS is not calibrated for complex, hardwood or uneven-aged stands or species mixes.

- Mixedwood Growth Model (MGM) is a model that was designed from the beginning to address mixed species stands, including anything from pure on one side to pure on the other side, with mixes in between. It is an individual tree oriented model, similar to TASS but without the spatial component.

- There is a juvenile stand component that is associated with MGM which attempts to grow trees from a relatively young age and then on into the older times. The original model was developed using Alberta data and has been validated and some comparisons with real data have been made to data from northeastern $\mathrm{BC}$ - a totally independent set of data from that used to calibrate it. Those projections and comparisons have been reasonably good.

- Currently GYPSY also has the ability to model commercial thinning or pre-commercial thinning of lodgepole pine. The most important feature here is that the GYPSY can also model the Alberta regeneration standards and it is compatible with Alberta guidelines, procedures and utilization standards. GYPSY can provide an estimate of what volume could be obtained by thinning and what kind of standing volume you could expect at any age of interest.

- There are a lot of things going on with growth and yield in the province - lot of different groups, three cooperatives in the formal sense at least, and everybody is doing different things.

\section{GROWTH AND YIELD DATA}

- As you start to subdivide the province you have to develop more growth relationships. More growth relationships means more data and as soon as you take a given pool of permanent sample plots and subdivide them ten times, all of a sudden you don't have enough data in any one sub-division to do a decent modeling effort for some of the relationships, or you have to augment with additional data.

- Regenerated yield assumptions have been based on putting back a fully stocked stand by meeting the standards, and using a fully stocked equivalent of those natural yield curves. This concept that the future will be a repeat of the past is not correct, as it is based on a false assumption. Today we just don't have a robust enough or a current enough indication of what is happening with stands once they have been harvested. We have to get to a system that ties what actual treatments and activities occur on the ground, and what information we need to collect over time, to validate those predicted height growths or volume growths or diameter distribution changes.

- In years to come things are going to get more sophisticated because we really are going to get down to the polygon level. One of the keys here is making sure we collect the right data and monitor performance so we can, over time, develop far better models and be able to demonstrate that to the world.

- Alberta has to get a good monitoring system in place and the data collected and fed into the AAC projection type of models. We could never validate individual stand growth and develop a system that would ensure that we could match every prediction, but we could develop a model that says, on average, what can be expected from a certain treatment, on a certain site. That is what the silviculturists need.

- Silvicultural groups who set the regeneration standards need to work closely with the growth modeling, mensuration \& inventory groups that try to use their data to project timber supply over time.

- Tools for modeling current forest growth are a separate but related issue from models for validating regenerated stand growth over time.

- Right now we cannot take the regeneration standard parameters as they are and actually project yield in MGM. We would have to convert add tree density and composition. The percent stocking of quadrates doesn't describe the way the density really looks.

- Government is not putting more stand dynamics plots in, they are just barely keeping the existing ones going. They don't have that many resources in terms of staff and money. In fact, thanks to the 
seismic industry, the number of PSPs is shrinking at the moment. They are trying to find ways to discourage seismic companies from harvesting on various kinds of PSPs.

- As the FMA holders' agreements are renewed the agreements are changed to require the companies to establish a growth \& yield program including PSPs.

- There are several things you can do at the PSP design phase. One is to ensure that PSPs are replaced immediately when they are cut and that they are tracked into the new stands. The G\&Y programs of new FMA holders need to target young stands.

- Part of the regeneration survey process should include a re-measurement beyond the 10 or 14 year point on some subset of the plots, which could begin to track actual height and diameter development relationships early in the life of the stand.

- We have a separate silviculture database, a separate growth and yield, and a separate timber supply analysis database. The three aren't tied together. We need some linkage between the planned the silviculture treatments to what is actually happening on the ground, and to build that into some system that we can use with some confidence for projecting future stand development over time.

- We need some set of PSPs that are representative of the stand types being harvested and the treatments applied, and the PSPs need to be consistently established and re-measured so that we can validate the models that we currently use or are in the process of developing.

- The internal relationships may change so you are going to have to have periodic reviews of the model itself.

- The government has data sharing agreements now where it can get FMA data for internal use but the data can't be redistributed to anyone else. There isn't a provincial pool of that data, but perhaps one could be developed if you could take off the locational portion of the information. In other words, the data could be stored based on ecological classification only. But ecosites in Alberta are not calibrated for site index yet. Sometimes researchers have found that two ecosites have the same site index. Sometimes two that are classified the same have very different site indices. Right now government is in the process of reviewing the boundaries of the ecological regions (called natural regions, subregions and districts)

- To kick start a growth \& yield program for regenerated stand density, other components are needed as well as some appropriate check off point where additional information is collected, a sort of second or third evaluation. Then long-term PSP data are needed to validate, prove, recalibrate, and redesign some of the computer models. With that data and those models you would have some degree of certainty around those predictions in the first place. Then there is the need for model validation over time. The acceptance of a model would be through some sort of peer review process. But in the end, you still have to compare the results of those models against actual data.

- A relatively small number of individuals exist within the companies, the government and the consultants who would correctly classify themselves as growth \& yield specialists. Government currently has 7 timber resource analysts that are involved in the DFMP review and the whole AAC determination. The real weak side is the focus on actual model development and validation, the more traditional mensurational component.

- If there was a more consistent framework for the FMP submission in terms of content and detail and a standardized set of protocols, that would simplify the review process.

- Over the last 5 years, the Auditor General's Office went through a validation process and was satisfied that the government tracked and documented the numbers as far as the approved AACs and the actual production by company. They want to understand how these models work. They are not just going to accept a black box because you tell them it works.

- Some of the pieces that are missing are this linkage from the silviculture side of the business to the long- term planning and monitoring .

- Government can't, from a cost perspective, have a PSP or series of PSPs on every single hectare or township of land in the province. So it must appropriately sample enough area by treatment regime, 
natural region, sub-region, ecosite, and have a standardized set of PSP protocols to generate a longterm perspective and then enough of the short term or temporary nature plot data that will bridge between the two worlds.

\section{MOVING TO MODEL II or MBO}

- Existing standards are required through a transition period until all DFMPs are fully developed (approximately 10 years).

- There will always be a portion of the industry which is never going to take the Model II approach and are just going to go with the minimums required by the government. Therefore, you still have to have some minimum requirement in this province.

- $\mathrm{MBO}$ (management by objective) is going to have to be initiated with the cooperation of industry. To make Model II more applicable on a larger portion of the landbase, you need to make it easier for them to come to conclusions together, as opposed to putting them in this situation where there is a zero-sum gain.

- The strongest disincentive to continue with Model I is to literally enforce the Model I framework for the allowable cut calculation process, so everything has to come back in those proportions. Then they can't do herbiciding on mixedwood stands, they can't do different types of treatments at the expense of one species over another. That becomes the overall disincentive, but it is not proactive in terms of moving to the next step.

- The simplest expansion to make Model I a Model II would be to move it from a cut block focus to a strata focus and then add more detail in terms of roles.

- You can maintain the commitments that exist today for the embedded operator and, at the same time, capture some better benefits for the primary species. Where it is working well, is where those secondary species exist in relatively minor amounts in terms of the overall AAC. It is also working where the primary holder has the rights to both conifer and deciduous and then it becomes a corporate decision as to whether or not you need that secondary species or not.

- There may be ultimate changes in the ratio of the conifer versus deciduous AAC but in so doing it is not to the detriment of that second party's allocation as it stands today. This happens when you roll all the stand types together, you don't calculate an AAC for a separate conifer line versus a separate deciduous line. You roll the two together, you have got a lot more flexibility. You can actually capture more allowable cut for the secondary species if you so choose.

- Need to pull together all the data that is required, all the different analyses that need to take place, defining of goals, objectives, strategies. Linkages have to be a lot more explicit. A lot of the issues around regenerated yield have to be dealt with in the context of sensitivity analysis.

\section{VOLUME SWAPS}

- On some of the smaller volumes, some of the companies are moving towards a volume supply agreement concept. They would rather have a fixed volume commitment than a quota percent.

- Ultimately it comes back to defining protocols for the allowable cut determination and what stand types contribute to which AAC.

- The government must ensure that the AACs that are approved reflect proper designation of land base and the proper designation of silvicultural treatments that get applied to maintain those AACs over time.

- Erasing administrative lines which become barriers to allowable cut calculation over the long term also spreads the impact of a catastrophic event.

- You have to keep the same proportions of conifer and deciduous, maybe you can increase it, increase the total volume but you can't change the ratios, you can't change the proportions. 
- You must keep your reforestation strata in line with the same ones that you used for prediction of your growth and yield outcomes. You probably need targets by strata, not by individual stands so it all depends on what stands make up strata.

\section{REFORESTATION OF BURNED AREAS AND OIL AND GAS DISTURBANCES}

- For larger fires, the burned area is taken out of the AAC calculation, a new post-fire AAC is calculated, then there is the opportunity to salvage that wood outside of the AAC. Areas that are planted are put back into the AAC calculation. It is up to the companies to decide if they want to reforest the salvage areas and bring them back into the AAC calculation now, as opposed to waiting for a regeneration survey or inventory to confirm their stocking status.

- If a company needs the AAC, and if the addition of more, younger stands actually helps lift the cut, it is likely to complete the reforestation. If the cut is constrained by the amount of mature timber in the unit, the cut is not likely to increase with reforestation, but the reforestation would help maintain the productive landbase.

- The way the oil and gas activity has been accounted for in the AAC process is through volume sampling programs. Where a plot lands on a seismic line, the volume per hectare is reduced. An actual area can now be applied to the linear features and treat them as landbase deductions.

\section{INVOLVEMENT OF PROFESSIONAL FORESTERS}

- There has been debate in Alberta about legislating that forest management plans have to be signed by a registered professional forester. That may not improve things, because they are being signed off by RPFs right now. The only thing they are not doing is being held personally responsible for it.

- Plans do not currently need to be signed by an RPF, but we are currently moving in that direction even though most companies already have an RPF or registered forest practitioner (RFP) signing.

- There is still the question of who is checking the quality of work carried out by professionals.

- The advantages of having Registered Professional Foresters responsible for Forest Management Plans include:

- Qualified persons are preparing and reviewing plans. Plans should be believable, deliverable, defendable, and sustainable.

- The individuals are required to keep their professional skills and knowledge up to date

- Diligence in carrying out their responsibilities is required

\section{PUBLIC INVOLVEMENT}

- Public involvement is intensive and ongoing. The first point for public involvement is when developing the terms of reference.

- Most companies have a public advisory committee which provides advice on their DFMP, preliminary harvest plans and annual operating plans. There is also public input on some practices such as herbicide application.

- The planning process is transparent

- The government is a stakeholder to ensure proper stewardship. It also has a technical advisory role.

- It has been difficult to obtain informed input on operations in the northern Boreal forest from the urban population in Edmonton and Calgary. Local input has been valuable and has been incorporated wherever possible into the DFMP.

- Financial assistance to public participants is usually limited to out of pocket expenses - their time is volunteered.

- The planning manual also requires performance monitoring and preparation of a stewardship report which is available to the public. 


\section{ENHANCED FOREST MANAGEMENT (EFM)}

The technical protocols for enhanced forest management were approved by the AFPA Forest Management Committee on February 4, 2000. The protocols identify acceptable methods, processes and standards for:

1. Forecasting and validating the effects of EFM

- Development of G\&Y models will be based on scientific evidence supporting the projected treatment response

- High quality, applicable data must be used to fit the projections

- Feasibility must be demonstrated

- Risk and uncertainty must be at an acceptable level

- Validation will occur within 10 years of treatment, be based on a statistically valid design which considers the risk and uncertainty of the forecast.

2. Setting performance standards

- Measures whether stands conditions meet those required to place stands on the proposed yield curve

- Measures are ecologically -based and objective-driven

- Targets are set for each stratum and treatment prescription in the management plan

3. Compliance monitoring

- Must demonstrate in the AOPs, compliance with the activities and treatment prescriptions committed to in the DFMP

- Monitoring will assess if the treatments have been applied as prescribed and whether the standards have been achieved

- Spatially referenced tracking systems will be required

- The Crown will require annual reports on EFM activities

4. Allocation rules

- Approval process begins with approval of the DFMP based on the planning manual. It requires participation of affected disposition holders. In the new forest management planning manual companies will be required to do sensitivity analyses for EFM proposals to project exactly what is going to happen should this new parameter come into play. The DFMP cannot be amended without appropriate public involvement and inter-departmental review and approval.

- Incremental AAC resulting from EFM practices should be allocated to the participating operators based on investment, without compromising the rights of, and commitments to, non-participating operators.

- Failure to meet standards will trigger and AAC impact assessment, and rescinding of ACE if required.

- An operator whose tenure is in good standing will be allocated the final harvest of any laterotation stand entered for commercial thinning, fertilization, or other treatment aimed at improving the quality of the timber, according to a treatment prescription and harvest schedule approved in the DFMP or DFMP amendment.

- An operator cannot be guaranteed access to the final harvest of individual stands treated earlier in the rotation, but will receive preferential access as long as the goals and objectives of the DFMP, current at the time of harvest, are not compromised. 
Appendix 4 - Presentations made to the Alberta Reforestation Standards Science Council

\section{Forest Industry Presentations}

Alberta Pacific Forest Industries Inc.

Alberta Newsprint Company

Diashowa-Marubeni International

Millar Western Forest Products Ltd.

Sunpine Forest Products / Spray Lakes Sawmills / Atlas Lumber (Alberta) Ltd.

Vanderwell Contractors (1971) Ltd.

Weldwood of Canada, Hinton Division

West Fraser Mills (Blue Ridge Lumber, Alberta Plywood, Slave Lake Pulp)

Weyerhaeuser Canada

\section{Non-Forest Industry Presentations}

Presenter

Dempster, Dick

Klappstein, Grant

Lautenschlager, R.A. / Dost, Frank / Mihajlovich, Milo

Morgan, Dave / Wang,

Shongming / Titus, Steve

Patterson, Dave

Price, Daryl

Rehsler, Paul

Thompson, Rory

\section{Topic}

Enhanced Forest Management Protocol

Overview of analysis and data for the 2000 Regeneration Standards

Herbicide Use in the Forest

Growth \& Yield Modeling in Alberta

Potential Improvements to the 2000 Regeneration Standards

AACs and Current Harvesting Levels in Alberta

Development of BC's Mixedwood Reforestation Standards

Forest Management Planning

\section{Written Submissions}

Alberta Sugarmakers Association

Canadian Parks and Wilderness Society

Whitecourt Public Advisory Committee 


\section{Appendix 5-Scientific Reviewers}

Jim Baker

Gordon Baskerville

Robin Brown

Dick Dempster

Brian Ferguson

Glen Jordan
Science Business Coordinator, Ontario Ministry of Forests Professor Emeritus, University of British Columbia Manager Silviculture Practices, BC Ministry of Forests Consultant, Dick Dempster Consulting, British Columbia Regional Silviculturist, US Department of Agriculture Professor, University of British Columbia 


National Library of Canada
Bibliothèque nationale du Cana

||||||||||||||||||||||U

|||||||||||||||||||||||||||||||||||||||||||||||||||||||||||

33286525476699 